\title{
Hofmeister Effect in the Keggin-type Polyoxotungstate Series
}

Received 00th January 20xx, Accepted 00th January 20xx

DOI: $10.1039 / x 0 x \times 00000 x$
Sa Yao, ${ }^{a}$ Clément Falaise, ${ }^{a}$ Anton A. Ivanov, ${ }^{a, b}$ Nathalie Leclerc, ${ }^{a}$ Max Hohenschutz, ${ }^{c}$ Mohamed Haouas, ${ }^{* a}$ David Landy, ${ }^{d}$ Michael Shestopalov, ${ }^{b}$ Pierre Bauduin, ${ }^{c}$ and Emmanuel Cadot*a

The chaotropic character of Keggin-type polyoxotungstate anions was evaluated with respect to their ability to bind to $\gamma$ cyclodextrin $(\gamma-C D)$ by varying the global charge density of the nanometer-sized polyanion. The strengths of the host-guest association were analyzed within the series of isostructural $\left[\mathrm{XW}_{12} \mathrm{O}_{40}\right]^{\mathrm{n}-\mathrm{r}}$ anions where ionic charge varies from 6- to 3depending on the heteroatom, respectively, $\mathrm{X}=\mathrm{H}_{2}{ }^{2+}, \mathrm{B}^{3+}, \mathrm{Si}^{4+}$ or $\mathrm{P}^{5+}$. Titration experiments using complementary techniques (ITC, DOSY NMR, and electrochemistry) revealed that the affinity between $\gamma$-CD and the polyoxometalate (POM) is directly correlated to the charge density of the Keggin anion as reflected in the values of the binding constants $\mathrm{K}_{1: 1}$. These constants increase dramatically following the order: $\left[\mathrm{H}_{2} \mathrm{~W}_{12} \mathrm{O}_{40}\right]^{6-}<\left[\mathrm{BW}_{12} \mathrm{O}_{40}\right]^{5-}<\left[\mathrm{SiW}_{12} \mathrm{O}_{40}\right]^{4-}<\left[\mathrm{PW}_{12} \mathrm{O}_{40}\right]^{3-}$. Additionally, cloud point experiments on a non-ionic surfactant resulted in the same series of POMs emphasize the general affinity of these inorganic Keggin-ions to non-ionic organic soft matter due to a general solvent effect arising from the weakening of the hydration sphere with decreasing ionic charge. Furthermore, single crystal X-ray diffraction analysis showed distinct organizations of the POMs with $\gamma-C D$ in the solid-state, where the moderate chaotrope $\left[\mathrm{BW}_{12} \mathrm{O}_{40}\right]^{5}$ interacts with the external wall of the $\gamma-C D$, while on the other side of the series, $\left[\mathrm{PW}_{12} \mathrm{O}_{40}\right]^{3-}$ penetrates deeply into the cavity of the $\gamma-C D$ through its secondary rim offering optimal contact area. Finally, our investigations revealed the unique behavior of $\left[\mathrm{PW}_{12} \mathrm{O}_{40}\right]^{3-}$, which displayed not only the highest affinity of the POMs to $\gamma-\mathrm{CD}\left(\mathrm{K}_{1: 1}>10^{5} \mathrm{M}^{-1}\right)$, but also the ability to interact with both $\mathrm{CD}$ faces resulting in a wide variety of supramolecular aggregates.

\section{Introduction}

Polyoxometalates (POMs) are a remarkable class of anionic polynuclear metal oxide clusters of transition metal ions like $\mathrm{W}^{\mathrm{VI}}$ or $\mathrm{Mo}^{\mathrm{VI}}{ }^{1}$. POMs are able to exchange reversibly and massively electrons without structural change, making them promising electro-active subcomponents of hybrid systems relevant for applications in the energy field. ${ }^{2}$ Recent studies highlighted that POMs are an appealing molecular 'electronreservoir' to construct lithium-, sodium-ion and redox flow batteries, $^{3-7}$ supercapacitors, $^{8}$ fuel cells ${ }^{9,10}$ or catalytic systems ${ }^{11-14}$ relevant for sustainable processes. The development of straightforward preparation routes to hybrid materials including POM units through supramolecular contacts has led to unique molecular assemblies with novel properties and reactivity. ${ }^{15}$ In context, exploration of ionic and other non-covalent interactions (hydrogen bonding, van der Waals forces, etc.) between POMs and other types of

\footnotetext{
a. Institut Lavoisier de Versailles, UMR 8180 CNRS, UVSQ, Université Paris-Saclay, Versailles, France.E-mail:mohamed.haouas@uvsq.fr,emmanuel.cadot@uvsq.fr

b. Nikolaev Institute of Inorganic Chemistry SB RAS, Novosibirsk, 630090, Russia.

c. ICSM, CEA, CNRS, ENSCM, Université de Montpellier, 34199 Marcoule, France.

${ }^{d}$. Unité de Chimie Environnementale et Interactions sur le Vivant (UCEIV, EA 4492),

ULCO, Dunkerque, France.

† Footnotes relating to the title and/or authors should appear here.

Electronic Supplementary Information (ESI) available: Additional experimental data (single crystal XRD, ITC, electrochemistry, NMR, SAXS and FT-IR spectroscopy). See DOI: $10.1039 / \times 0 \times x 00000 x$
}

molecular systems has attracted considerable interest, revealing the remarkable supramolecular behavior of POMs to self-assemble across multiple length scales ranging from discrete systems to gigantic spherical single-layered nanostructures known as "blackberries". ${ }^{12,16-20}$

One of the most striking supramolecular properties of POMs arises from their ability to form in solution resilient nonbonding contacts with neutral surfaces such as organic macrocycles, micelles, proteins or polymers. ${ }^{21-30}$ Actually, their solution behavior appears "counter-intuitive" because POMs are anionic inorganic discrete species considered generally as hydrophilic. Others and us established that association phenomena between POMs and organic moieties are driven by a solvent mediated effect arising from a water structure recovery upon release of the POM's and the moiety's hydration water. ${ }^{22,26,31}$ POMs as well as other polynuclear species (dodecaborates or electron-rich octahedral clusters) have been identified as water structure breakers, also named chaotropic entities after the Hofmeister classification. ${ }^{22,32-34}$ Based on the current understanding of the Hofmeister series, the chaotropicity of an ion should increase when its charge density decreases, but regarding POMs more insight is needed into the influence of the ionic charge, especially the effect of redox change on their chaotropic character. ${ }^{22,31}$ From a thermodynamic point of view, processes involving chaotropes are usually considered to be enthalpically driven accompanied by an entropic penalty, i.e. enthalpy-entropy compensation. ${ }^{26,35}$ 
Cyclodextrins (CDs) are natural cyclic oligosaccharides with a hydrophobic internal cavity and a hydrophilic external surface, and thus exhibit interesting properties as host molecules for a wide variety of inorganic species including polyoxometalates. ${ }^{36} \mathrm{CDs}$ are readily available as $\alpha$-, $\beta$ - and $\gamma$ forms comprising six, seven, or eight glucose units, respectively. The host-guest assembly of the toroidal CDs and spherical POM clusters has attracted much attention and is a fast-growing topic. In 2015, Stoddart and coworkers published the first examples of host-guest complexes between $\gamma$ - and $\beta$ $\mathrm{CDs}$ and phosphomolybdate $\left[\mathrm{PMO}_{12} \mathrm{O}_{40}\right]^{3-} \cdot{ }^{30}$ Since then, several hybrid (organic/inorganic) adducts or materials have also been reported with various archetypal polyoxotungstates including the Lindqvist-type $\left[\mathrm{W}_{6} \mathrm{O}_{19}\right]^{2-37,38}$ the Keggin-type ions $\left[\mathrm{PW}_{12} \mathrm{O}_{40}\right]^{3-}$ and $\left[\mathrm{SiW}_{12} \mathrm{O}_{40}\right]^{4-, 3^{-384}}$ and the Dawson-type $\left[\mathrm{P}_{2} \mathrm{~W}_{18} \mathrm{O}_{62}\right]^{6-25,26}$ Some of these hybrid CD/POM materials are promising for application in catalysis ${ }^{39,41}$ and energy storage, ${ }^{44}$ where surface effects and hybrid structure would play crucial role. Therefore, detailed characterization of the interactions between CDs and POMs and a better understanding of the phenomena occurring on their interfaces are essential for further innovative developments of redox-responsive systems and related applications.
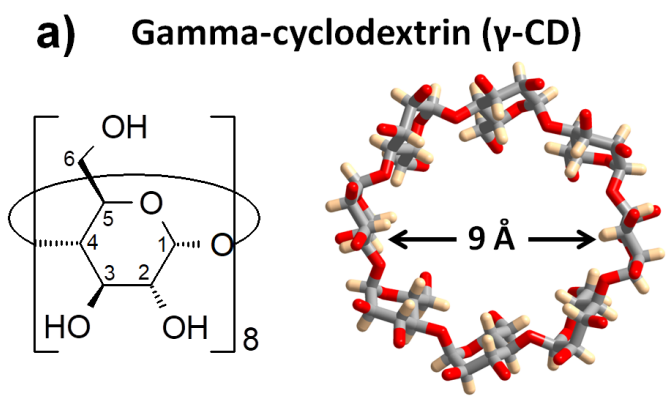

\section{b) Keggin anion $\left[\mathrm{XW}_{12} \mathrm{O}_{40}\right]^{\mathrm{n}-}$}
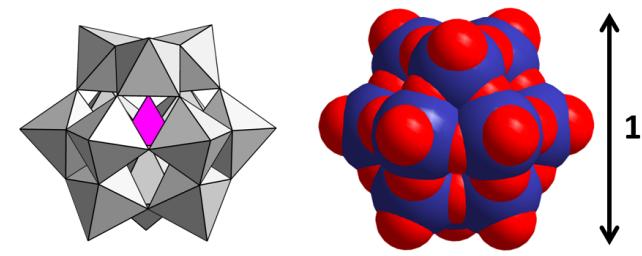

$10.5 \AA$

\section{$\left[\mathrm{PW}_{12} \mathrm{O}_{40}\right]^{3-}\left[\mathrm{SiW}_{12} \mathrm{O}_{40}\right]^{4-}\left[\mathrm{BW}_{12} \mathrm{O}_{40}\right]^{5-}\left[\mathrm{H}_{2} \mathrm{~W}_{12} \mathrm{O}_{40}\right]^{6}$ Charge density}

Fig. 1 Structural representations of the molecular entities used as building blocks. (a) $\gamma$ cyclodextrin $\mathrm{C}_{48} \mathrm{H}_{80} \mathrm{O}_{40}(\gamma-\mathrm{CD})$ resulting from the condensation of eight glycopyranose units. The toroidal macrocycle delimits a hydrophobic cavity of $9 \AA$ in diameter. (b) The Keggin-type POM, $\left[\mathrm{XW}_{12} \mathrm{O}_{40}\right]^{\mathrm{n}-}$, composed of twelve octahedral $\mathrm{WO}_{6}$ polyhedra that form an anionic tetrahedral cage $\left\{\mathrm{W}_{12} \mathrm{O}_{40}\right\}^{8-}$ with a central cavity occupied by the heteroatom $X\left(\mathrm{P}^{5+}, \mathrm{Si}^{4+}, \mathrm{B}^{3+}\right.$ or $\left.\mathrm{H}_{2}{ }^{2+}\right)$. The choice of $\mathrm{X}$ allows the control of the charge density of the nano-sized inorganic POM.

Herein, we study the formation of host-guest inclusion complexes of $\gamma-C D$ and Keggin-type POM anions along the $\left[\mathrm{XW}_{12} \mathrm{O}_{40}\right]^{\mathrm{n}-}$ series with anionic charges from 3- to 6- (Fig. 1) while keeping constant the shape and size of the host and of the guest. Using a set of complementary techniques (NMR, ITC and electrochemistry), we show in this article that affinity between $\gamma-C D$ and Keggin-type anions increases dramatically with decreasing ionic charge. Simultaneously, we evaluate the chaotropic behavior using a simple experimental procedure based on the propensity of the POM species to adsorb on the non-ionic ethylene glycol-based surfactant $\mathrm{C}_{8} \mathrm{E}_{4}$. Thus, we establish unambiguously in this report the direct correlation between the chaotropic nature and the formation of highly stable supramolecular complexes. The present study might open new opportunities for the development of smart supramolecular devices with responsive behavior based on redox changing of the POM unit.

\section{Results and discussion}

\section{Synthesis}

Attempts for isolation of the supramolecular adducts have been carried out systematically using different ratios of sodium salt of POMs $\mathrm{Na}_{m}\left[\mathrm{XW}_{12} \mathrm{O}_{40}\right] \cdot \mathrm{nH}_{2} \mathrm{O}$ with $\mathrm{X}=\mathrm{P}^{5+}, \mathrm{Si}^{4+}, \mathrm{B}^{3+}, \mathrm{H}_{2}{ }^{2+}$ and varying procedures of crystallization such as slow evaporation of aqueous solution or ethanol vapor diffusion into aqueous solution containing cesium chloride. In all cases, crystalline products were obtained but only $\left[\mathrm{BW}_{12} \mathrm{O}_{40}\right]^{5-}$ and $\left[\mathrm{PW}_{12} \mathrm{O}_{40}\right]^{3-}$ led to single crystals suitable for XRD analysis. Their composition was established combining different complementary techniques (elemental analysis, EDS, XRD, and TGA). The compounds $\mathrm{CsK}_{2} \mathrm{H}_{2}\left\{\left[\mathrm{BW}_{12} \mathrm{O}_{40}\right] \cdot 2(\gamma-\mathrm{CD})\right\} \cdot 29 \mathrm{H}_{2} \mathrm{O}$ $\left(\mathrm{BW}_{12} \bullet 2 \mathrm{CD}\right)$ and $\mathrm{Na}_{3}\left\{\left[\mathrm{PW} \mathrm{W}_{12} \mathrm{O}_{40}\right] @(\gamma-\mathrm{CD})\right\} \cdot 10 \mathrm{H}_{2} \mathrm{O}\left(\mathbf{P W}_{12} @ \mathrm{CD}\right)$ present different molecular organization as further discussed in the next section.

\section{Review of Keggin $/ \gamma$-CD interactions in the solid-state}

The crystal structure of $\mathbf{P W}_{\mathbf{1 2}} @ \mathbf{C D}$ was found to be isostructural to the recently published compounds $\mathrm{NaAH}_{6}\left[\left(\mathrm{PW}_{12} \mathrm{O}_{40}\right)_{3}(\gamma-\mathrm{CD})_{3}\right] \cdot \mathrm{nH}_{2} \mathrm{O}\left(\mathrm{A}=\mathrm{CO}^{\prime \prime}\right.$ or $\left.\mathrm{Cu}^{\prime \prime}\right) .^{45}$ Zhan and coworkers introduced $\mathrm{Co}\left(\mathrm{NO}_{3}\right)_{2}$ or $\mathrm{CuSO}_{4}$ to aqueous solutions containing $\gamma-\mathrm{CD}$ and $\mathrm{Na}_{3}\left[\mathrm{PW}_{12} \mathrm{O}_{40}\right]$ to obtain crystalline products. ${ }^{43}$ In our case, only $\mathrm{Na}^{+}$and $\mathrm{H}^{+}$were present evidencing that the POM-CD packing in $\mathbf{P W}_{\mathbf{1 2}} @ \mathbf{C D}$ is highly flexible to accommodate various types of counter-cations without structural change. PW 12 @CD's structure consists of a supramolecular $1: 1$ adduct involving a $\left[\mathrm{PW}_{12} \mathrm{O}_{40}\right]^{3-}$ unit partially incorporated into the cavity of $\gamma$-CD through its secondary rim (Fig. 2a). This configuration is quite unique among the few known polyoxometalate $/ \gamma-C D$ composites that mostly feature interactions with the primary face. ${ }^{26,30}$ of particular interest, comparison with the isostructural Keggin phosphomolybdate $\left[\mathrm{PMO}_{12} \mathrm{O}_{40}\right]^{3-}$ reveals a different complexation mode with $\gamma-\mathrm{CD}$ involving the opposite face, namely, the primary rim (Fig. 2b). ${ }^{30}$ Furthermore, the stoichiometry of the $\left[\mathrm{PMO}_{12} \mathrm{O}_{40}\right]^{3-}: \mathrm{CD}$ adduct is $1: 2$, while a $1: 1$ stoichiometry was found with $\left[\mathrm{PW}_{12} \mathrm{O}_{40}\right]^{3-}$ although higher stoichiometry numbers should be expected as observed with Dawson-type POM with stoichiometry of 1:1 up to $1: 3 .^{\mathbf{2 6}}$ Indeed, while $\mathbf{P W}_{\mathbf{1 2}} @ \mathbf{C D}$ crystallized in a 1:1 solution mixture, other crystalline products were obtained with higher $\gamma$-CD contents $(2 \gamma$-CDs per POM 
unit), but we were unable, despite numerous repeated attempts, to solve the solid-state structures of these crystals featuring a tetragonal unit cell ( $a=b=23.94$ and $c=18.54 \AA$ ). The 1:1 adduct observed in $\mathbf{P W}_{\mathbf{1 2}} @ \mathbf{C D}$ exhibits several nonbonding contacts involving the terminal $\mathrm{O}^{t}$ and bridging $\mathrm{O}^{\mathrm{b}}$ atoms of the POM and $\mathrm{H} 3$ and $\mathrm{H} 5$ protons (see Fig. 1a for $\mathrm{H}$ labeling) of the inner cavity of the $\gamma-C D$ (see Fig. S1, in ESI). The short interatomic distances $\mathrm{H} 3 \bullet \bullet \mathrm{O}^{\mathrm{t}}=\mathrm{W}$ (from 2.69 to $3.31 \AA$ ), $\mathrm{H} 3 \bullet \bullet \bullet \mathrm{O}^{\mathrm{b}}-\mathrm{W}$ (from 2.41 to $2.88 \AA$ ) , $\mathrm{H} 5 \cdot \bullet \cdot \mathrm{O}^{\mathrm{t}}=\mathrm{W}$ (from 2.29 to $3.38 \AA$ ) , and $\mathrm{H} 5 \bullet \bullet \cdot \mathrm{O}^{\mathrm{b}}-\mathrm{W}$ (from 3.13 to $3.88 \AA$ ) reflect a strong and deep host-guest inclusion. As $\mathbf{P W}_{\mathbf{1 2}} @ \mathbf{C D}$ crystallizes in a cubic crystallographic system, the 1:1 host-guest adduct is surrounded by four host-guest units giving additional nonbonding contacts between the exposed face of the Keggin ion and the external surface of each of the neighboring $\gamma$-CDs (see Fig. S2, in ESI).

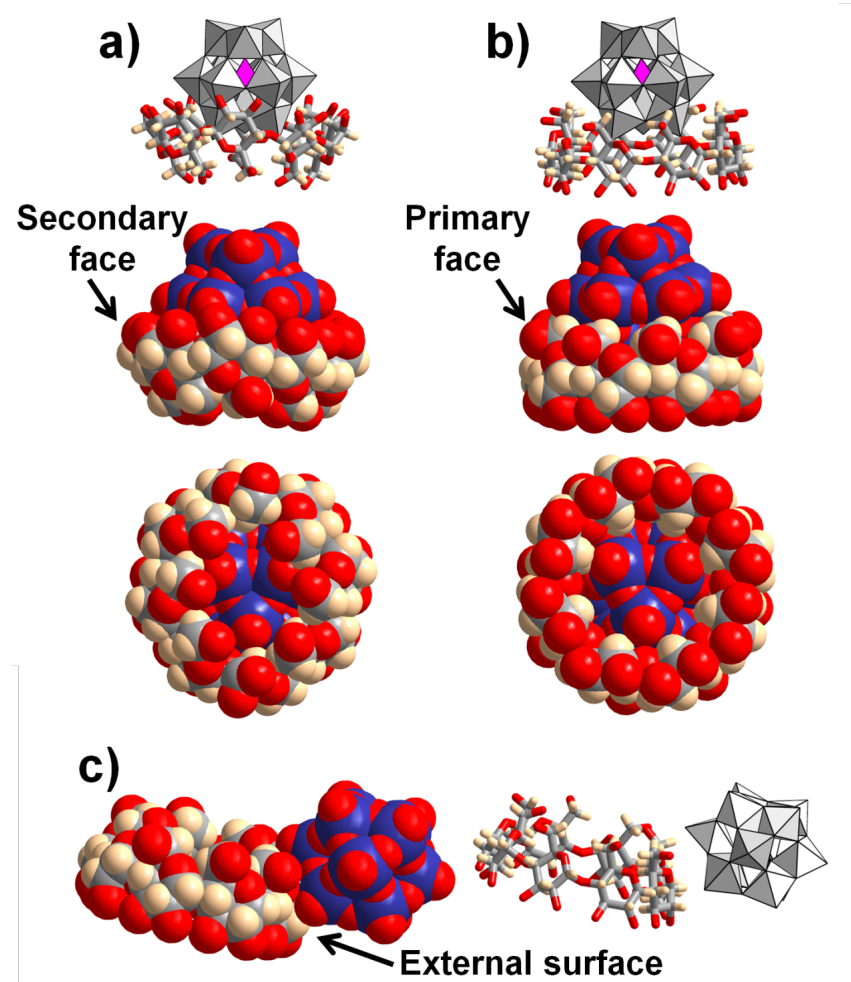

Fig. 2 Illustration of the different supramolecular assemblies observed in the solid-state involving $\gamma-C D$ and the Keggin anions (a) $\left[\mathrm{PW}_{12} \mathrm{O}_{40}\right]^{3-}$ in $\mathrm{PW}_{12} @ C D$, (b) $\left[\mathrm{PMo}_{12} \mathrm{O}_{40}\right]^{3-}$ from reference ${ }^{30}$, and (c) $\left[\mathrm{BW}_{12} \mathrm{O}_{40}\right]^{5-}$ in $\mathbf{B W}_{12} \cdot \mathbf{2 C D}$.

In the solid-state, the organization of the $\left[\mathrm{BW}_{12} \mathrm{O}_{40}\right]^{5-}$ and $\gamma-$ $C D$ is significantly different since the crystalline structure of $\mathbf{B W}_{\mathbf{1 2}} \bullet \mathbf{2 C D}$ reveals that the two components co-crystallize without forming an inclusion complex. Indeed, the $\left[\mathrm{BW}_{12} \mathrm{O}_{40}\right]^{5-}$ is positioned near the $\gamma-C D$ in close contact with its external wall (Fig. 2c). One $\left[\mathrm{BW}_{12} \mathrm{O}_{40}\right]^{5-}$ unit is surrounded by eight $\gamma$-CDs and each $\gamma-C D$ is in contact with four $\left[\mathrm{BW}_{12} \mathrm{O}_{40}\right]^{5-}$ through the three outward protons $\mathrm{H} 1, \mathrm{H} 2$, and $\mathrm{H} 4$ as well as the $\mathrm{H} 6$ of the methoxy arm (see Fig. S3, ESI). This leads to a global stoichiometry of 2( $\gamma-C D): 1 P O M$. Two neighboring $\gamma$-CDs are face-to-face connected through a hydrogen bonding network from their secondary rims. The $\left[\mathrm{BW}_{12} \mathrm{O}_{40}\right]^{5-}$ is therefore positioned near the primary face with $\mathrm{H} 6 \cdot \bullet \cdot \mathrm{O}^{\mathrm{t}}=\mathrm{W}$ and $\mathrm{H} 6 \bullet \bullet \mathrm{O}^{\mathrm{b}}-\mathrm{W}$ distances in the 2.66-2.91 $\AA$ and 2.73-3.91 range, respectively. This arrangement with empty $\gamma$-CDs is unique in $\mathrm{POM} / \gamma-\mathrm{CD}$ composites although it could occur with the smaller $\alpha-C D .^{44}$ Indeed, the $\left[\mathrm{PW}_{12} \mathrm{O}_{40}\right]^{3-}$ Keggin anion led to an extended framework with $\alpha-C D$ forming double layers of interconnected $\left[\mathrm{PW}_{12} \mathrm{O}_{40}\right]^{3-}$ and $\mathrm{CD}$ motifs through bridging alkali cations. ${ }^{44}$ This highlights the importance of the sizematching effect upon the molecular recognition process, ${ }^{46}$ however this could not explain the difference of binding interactions observed in Keggin $/ \gamma$-CD arrangement.

Finally, it is surprising to see how $\gamma-C D$ interacts so differently with isostructural nano-sized objects, namely $\left[\mathrm{PW}_{12} \mathrm{O}_{40}\right]^{3-},\left[\mathrm{PMO}_{12} \mathrm{O}_{40}\right]^{3-}$, and $\left[\mathrm{BW}_{12} \mathrm{O}_{40}\right]^{5-}$. By keeping the charge constant, the basicity of Keggin molybdates is known to be stronger compared to their tungstate analogues as the charge density is higher on the oxygen atoms at the surface of the molybdates. ${ }^{47,48}$ Furthermore, the ionic charge must also play a crucial role in the supramolecular association. ${ }^{21}$ Both these aspects are expected to affect significantly solvent structuration around the POM, and should have important consequences in the formation and stability of the resulting POM-based supramolecular arrangement. Systematic studies in solution are thus needed to shed light on such effects.

\section{Stability in solution}

To investigate the complexation of the Keggin-type anions by $\gamma-C D$, titration experiments were conducted in solution by means of a set of complementary techniques including NMR spectroscopy $\left({ }^{1} \mathrm{H} \quad\right.$ 1D and DOSY), electrochemistry, and isothermal titration calorimetry (ITC).

\section{Isothermal titration calorimetry}

ITC experiments were carried out to determine the thermodynamical fingerprint of the interaction of $\gamma-C D$ respectively with the four Keggin-type heteropolytungstates. ITC thermograms and isotherms are shown in the Electronic Supplementary Information (see Figs. S4-6, ESI), and a summary of binding constants, enthalpy $\Delta_{\mathrm{r}} H^{*}$ and entropy $\Delta_{\mathrm{r}} S^{*}$ changes are given at $298 \mathrm{~K}$ in Table 1 . Beside the $1: 1$ complexation, a second $1: 2$ step process is systematically considered, according to equations ( 1 ) and (2) shown below.

$$
\begin{array}{ll}
\mathrm{POM}^{\mathrm{n}-}+\mathrm{CD} & \rightarrow[\mathrm{POM} @ \mathrm{CD}]^{\mathrm{n}-} \\
{[\mathrm{POM} @ C D]^{\mathrm{n}-}+\mathrm{CD}} & \rightarrow[\mathrm{POM} @ 2 \mathrm{CD}]^{\mathrm{n}-}
\end{array}
$$

Nonetheless, only ITC data for silicotungstate were found consistent with the 2:1 binding model involving a sequential process. No significant heat exchange was observed in the case of $\left[\mathrm{H}_{2} \mathrm{~W}_{12} \mathrm{O}_{40}\right]^{6-}$ indicating negligible interactions with $\gamma$-CD. For all other complexes, supramolecular binding revealed to be enthalpically driven. The enthalpic gain is accompanied by an entropic penalty according to the usual enthalpy-entropy compensation observed within CD-based host-guest series. ${ }^{\mathbf{4 9}}$ These thermochemical fingerprints together with low values of both enthalpic and entropic changes suggests that Keggin 
anions behave as chaotropic species (water structure breakers). ${ }^{31}$ In such a case, the magnitude of the chaotropic character and the related binding constants are expected to increase with decreasing global charge. However, the highest enthalpic and entropic changes (and binding constants), were observed for $\left[\mathrm{SiW}_{12} \mathrm{O}_{40}\right]^{4-}$ and the lowest values were found for $\left[\mathrm{PW}_{12} \mathrm{O}_{40}\right]^{3-}$. This result represents therefore an anomaly within the expected series, as confirmed by the electrochemical and NMR studies discussed below. The discrepancy here may have appeared for two reasons: i) the partial hydrolysis of the $\left[\mathrm{PW}_{12} \mathrm{O}_{40}\right]^{3-}$ anion in the ITC conditions (non-buffered and diluted solution) or ii) the simultaneous formation of numerous complexes with various stoichiometries, e.g. 1:1, 1:2, 2:1, etc., (overparametrization).

Table 1 Binding constants $\left(\mathrm{M}^{-1}\right)$ of $\gamma$-CD with the Keggin-type POMs and associated thermodynamic parameters $\left(\mathrm{kJ} \cdot \mathrm{mol}^{-1}\right)$ at $T=298 \mathrm{~K}$ measured by ITC. Calculated uncertainties are inferior to $10 \%$.

\begin{tabular}{cccccc}
\hline POM & POM:CD & $K$ & $\Delta_{\mathrm{r}} H^{*}$ & $T \Delta_{\mathrm{r}} S^{*}$ & $\Delta_{\mathrm{r}} \mathrm{G}^{*}$ \\
\hline$\left[\mathrm{H}_{2} \mathrm{~W}_{12} \mathrm{O}_{40}\right]^{6-}$ & - & - & - & - & - \\
{$\left[\mathrm{BW}_{12} \mathrm{O}_{40}\right]^{5-}$} & $1: 1$ & 1032 & -53.5 & -36.3 & -17.2 \\
{$\left[\mathrm{SiW}_{12} \mathrm{O}_{40}\right]^{4-}$} & $1: 1$ & 17209 & -56.4 & -32.3 & -24.2 \\
& $1: 2$ & 459 & -55.0 & -39.8 & -15.2 \\
& $1: 1$ & 2919 & -35.1 & -15.3 & -19.8 \\
\hline $\left.\mathrm{PW}_{12} \mathrm{O}_{40}\right]^{3-}$ & $1: 1$ & & &
\end{tabular}

\section{Electrochemical studies}

Interactions of the Keggin-type ions with $\gamma-C D$ have been studied further using cyclic voltammetry. As shown below, the presence of $\gamma$-CD alters significantly the redox properties of the POMs. Besides, the POM's redox state is expected to have high impact on the binding constants. As shown in Fig. 3, dependence of CVs with $\gamma$-CD appears strongly dependent on the nature of the Keggin anion.

For instance, as the amount of $\gamma$-CD increases up to 8 equivalents, the half-wave potential related to the two first monoelectronic transfers of the $\left[\mathrm{PW}_{12} \mathrm{O}_{40}\right]^{3-}$ ion decreases continuously (see Fig. 3). Actually, the electrochemical behavior of the $\left[\mathrm{PW}_{12} \mathrm{O}_{40}\right]^{3-}$ ion gives the most representative effect reflected by a rough dependency of about $-60 \mathrm{mV} / \mathrm{pCD}$ where $p C D=-\log [C D]$ (see Fig. S9, ESI). This variation indicates that $\gamma$-CD is involved in the predominant redox process written in equation (3), with two consecutive monoelectronic transfers, $n=3$ or 4 for the first and the second redox processes, respectively. Furthermore, the complexation behavior of $\gamma-C D$ should be rather consistent with $x=2$ or 1 corresponding to a 2:1 and 1:1 supramolecular adduct, respectively.

$\left.\left[\operatorname{POM}(C D)_{x}\right]^{n-}+1 e-\rightarrow \operatorname{POM}(C D)_{x-1}\right]^{(n+1)-}+C D$
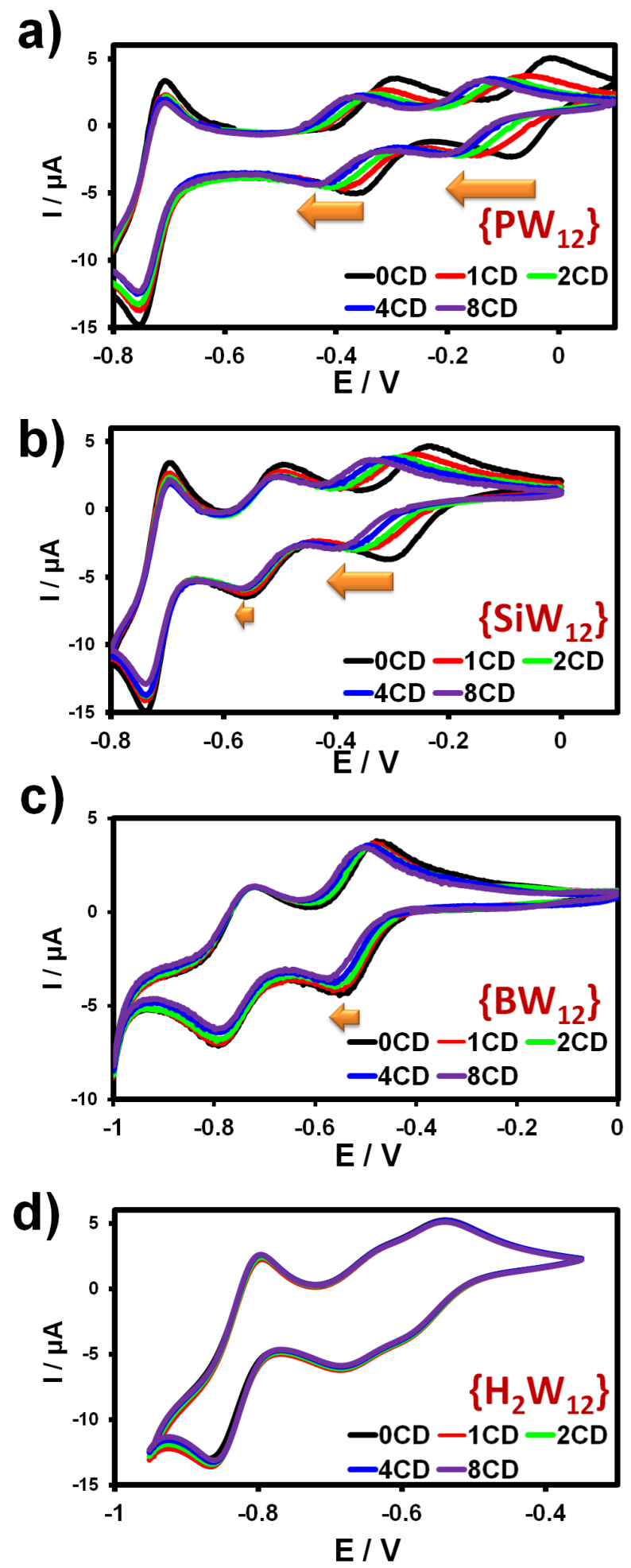

Fig. 3 Cyclic voltammetry of the $\left[\mathrm{XW}_{12} \mathrm{O}_{40}\right]^{\mathrm{n}-}$ anions with (a) $\mathrm{X}=\mathrm{P}^{5+}$, (b) $\mathrm{Si}^{4+}$, (c) $\mathrm{B}^{3+}$ or (d) $\mathrm{H}_{2}{ }^{2+}\left(0.5 \mathrm{mmol} . \mathrm{L}^{-1}\right.$, glassy carbon working electrode, scan rate $\left.50 \mathrm{mV} . \mathrm{s}^{-1}\right)$ in the presence of increasing amounts of $\mathrm{Y}-\mathrm{CD}$ (from 0 to 8 equivalents). The experiments involving $\left[\mathrm{PW}_{12} \mathrm{O}_{40}\right]^{3-},\left[\mathrm{SiW}_{12} \mathrm{O}_{40}\right]^{4-}$ and $\left[\mathrm{BW}_{12} \mathrm{O}_{40}\right]^{5-}$ have been performed in $25 \mathrm{mmol} . \mathrm{L}^{-1}$ $\mathrm{HClO}_{4}$ aqueous solution, while acetate buffer solution $\left(0.5 \mathrm{M} \mathrm{CH}_{3} \mathrm{COONa} ; 0.5 \mathrm{M}\right.$ $\mathrm{CH}_{3} \mathrm{COOH}$ ) has been used for the electrochemical measurements of $\left[\mathrm{H}_{2} \mathrm{~W}_{12} \mathrm{O}_{40}\right]^{6-}$. 
Along the Keggin series, the variation of the redox properties becomes less pronounced as the ionic charge of the Keggin ion increases. Thus, in the case of $\left[\mathrm{SiW}_{12} \mathrm{O}_{40}\right]^{4-}$, the first mono-electronic redox wave appears strongly affected, whereas the second one varies weakly. For the boron derivative, only the first redox wave is moderately shifted and finally, the redox features of $\left[\mathrm{H}_{2} \mathrm{~W}_{12} \mathrm{O}_{40}\right]^{6-}$ remain nearly unchanged in the presence of $\gamma-C D$ (see Fig. 3). With the exception of $\left[\mathrm{PW}_{12} \mathrm{O}_{40}\right]^{3-}$, the redox behavior reflects the trend highlighted by the ITC analysis.

Quantitative analysis of these electrochemical data can yield the equilibrium constants $\left(K_{1: 1}\right.$ and $\left.K_{1: 2}\right)$ regarding the binding of the Keggin anions at various redox states by the $\gamma$ $C D$. Considering the three available oxidation states of $\mathrm{POM}^{\mathrm{n}-}$ $(o x), P^{(n+1)-}\left(\operatorname{red}_{1}\right), \mathrm{POM}^{(\mathrm{n}+2)-}\left(\operatorname{red}_{2}\right)$, associated to the three related complexed forms POM@xCD with $\mathrm{x}=0,1$ or 2 , the $3 \times 3$ matrix diagram can be drawn (see scheme 1 ).

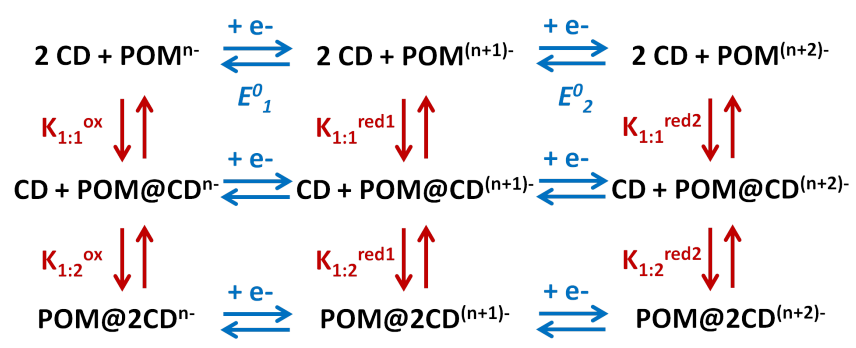

Scheme 1 Equilibriums involved in redox-dependent supramolecular association of $\gamma$ cyclodextrin (CD) and the Keggin type anions (POM).

Including the six redox components involved in each redox process, the Nernst equations are written as followed:

$E_{\text {peak }, 1}=E_{1}^{0}+\frac{R T}{F} \ln \frac{\left(1+K_{1: 1}^{o x}[C D]_{e q}+K_{1: 1}^{o x} K_{1: 2}^{o x}[C D]_{e q}^{2}\right)}{\left(1+K_{1: 1}^{r e d 1}[C D]_{e q}+K_{1: 1}^{r e d 1} K_{1: 2}^{r e d 1}[C D]_{e q}^{2}\right)}$

$E_{\text {peak }, 2}=E_{2}^{0}+\frac{R T}{F} \ln \frac{\left(1+K_{1: 1}^{r e d 1}[C D]_{e q}+K_{1: 1}^{r e d 1} K_{1: 2}^{r e d 1}[C D]_{e q}^{2}\right)}{\left(1+K_{1: 1}^{r e d 2}[C D]_{e q}+K_{1: 1}^{r e d 2} K_{1: 2}^{r e d 2}[C D]_{e q}^{2}\right)}$

where $E_{1}^{0}$ or $E_{2}^{0}$ are the standard potentials of each redox process and $[C D]_{\mathrm{eq}}$, the concentration in free $\mathrm{\gamma}-\mathrm{CD}$ at the equilibrium. The values $K_{1: 1}$ and $K_{1: 2}$ correspond to the binding constants associated to equation (1) and (2), respectively, wherein the POM can be in its three redox states, oxidized (ox), one-electron reduced (red1) or two-electron reduced (red2) (see scheme 1). Depending on the Keggin-type POM, equations (4) or (5) were adapted and then used to extract the binding constants through the fitting of experimental shift of the apparent potential upon free $\gamma$-CD concentration (see ESI, Figs. S7-9). The case of the metatungstate ion $\left[\mathrm{H}_{2} \mathrm{~W}_{12} \mathrm{O}_{40}\right]^{6-}$ is trivial as neither ITC nor electrochemistry evidences any interaction with $\gamma$-CD. For the $\left[\mathrm{BW}_{12} \mathrm{O}_{40}\right]^{5-}$ ion, ITC experiments showed formation of a 1:1 adduct. Furthermore, the second wave is nearly independent of the $\gamma-C D$ concentration meaning that the one-electron and the two-electron reduced forms do not interact with $\gamma-C D$. In such conditions, the expression of the apparent potential $E_{\text {peak, } 1}$ is adapted from equation (4) by using only the binding constant $K_{1: 1}^{o x}$. Decreasing further the ionic charge produces a richer and more complex behavior.
The first wave of the $\left[\mathrm{SiW}_{12} \mathrm{O}_{40}\right]^{4-}$ anion undergoes a shift of about $-60 \mathrm{mV}$ per $p C D$ unit (see ESI, Fig. S8) meaning the Nernst Equation can be derived from equation (3). The second wave exhibits only moderate variation, consistent with a weak complexation of the one-electron reduced form $\left(\mathrm{red}_{1}\right)$ and no complexation for the two-electron reduced form $\left(\operatorname{red}_{2}\right)$. Then the equation (5) is derived by using only the binding constant $K_{1: 1}^{r e d_{1}}$ and matches the experimental data for $K_{1: 1}^{r e d_{1}}=130 \mathrm{M}^{-1}$. Considering the first monoelectronic exchange, both the 1:1 and the $1: 2$ adduct must be considered for the oxidized form as shown by ITC. Then equation (4) should include $K_{1: 1}^{o x}, K_{1: 2}^{o x}$ and $K_{1: 1}^{r e d_{1}}=130 \mathrm{M}^{-1}$. Suitable fitting with experimental data was obtained with numerical values 9500 and $150 \mathrm{M}^{-1}$ for $K_{1: 1}^{o x}$ and $K_{1: 2}^{o x}$, respectively. Finally, the electrochemical behavior of the $\left[\mathrm{PW}_{12} \mathrm{O}_{40}\right]^{3-}$ ion consists of two CD-dependent monoelectronic waves which move both by about $-60 \mathrm{mV}$ per $p C D$ unit in accordance with equation (3). The second wave is satisfactory modeled by using $K_{1: 1}^{r e d_{1}}=6000 \mathrm{M}^{-1}$ and $K_{1: 2}^{r e d_{1}}=30 \mathrm{M}^{-}$ ${ }^{1}$ while calculation of the first redox potentials requires to include $K_{1: 1}^{o x}$ and $K_{1: 2}^{o x}$ in addition to the binding constants related to the reduced form $\left[\mathrm{PW}_{12} \mathrm{O}_{40}\right]^{4-}$, namely $\mathrm{red}_{1}$. From equation (4), good agreement was found between calculated and experimental data for $K_{1: 1}^{o x}=90000 \mathrm{M}^{-1}$ and $K_{1: 2}^{o x}=1500$ $\mathrm{M}^{-1}$. The overall binding constants values are reported in Table 2 and the comparison between experimental data and the simulated evolution of the observed apparent potential is reported in ESI (see Figs. S7-9). The binding constants determined by electrochemistry for $\left[\mathrm{BW}_{12} \mathrm{O}_{40}\right]^{5-}$ and $\left[\mathrm{SiW}_{12} \mathrm{O}_{40}\right]^{4-}$ ions are significantly lower compared to those found by ITC (see Table 1). This difference is likely due to the different medium used in the ITC experiments (pure water) and in the electrochemical measurements (aqueous solution of $0.025 \mathrm{~mol}^{-1} \mathrm{HClO}_{4}$ ) and may arise from the presence of hydronium ions $\mathrm{H}_{3} \mathrm{O}^{+}$or perchlorate ion $\mathrm{ClO}_{4}^{-}$involved in competition processes with the POM-CD aggregation. Importantly, analysis of the electrochemical data allows us to determine the $K_{1: 1}$ binding constants of the $\left[\mathrm{PW}_{12} \mathrm{O}_{40}\right]^{3-}$ ion. With a value of $9 \times 10^{4} \mathrm{M}^{-1}$, the affinity of $\left[\mathrm{PW}_{12} \mathrm{O}_{40}\right]^{3-}$ for $\mathrm{Y}-\mathrm{CD}$ is about one order of magnitude higher than the affinity of $\left[\mathrm{SiW}_{12} \mathrm{O}_{40}\right]^{4-}$. Such a high value corresponds to one of the largest affinity constants reported so far with $y-C D . .^{32,50,51}$ Moreover, the second binding constant $K_{1: 2}$ is also quite large, around one order of magnitude higher than the $K_{1: 2}$ value observed for $\left[\mathrm{SiW}_{12} \mathrm{O}_{40}\right]^{4-}$. 
Table 2 Binding constants $K_{1: 1}$ and $K_{1: 2}$ involving $\gamma$-CD with the Keggin-type anions at different oxidation states as determined from electrochemistry. The accuracy is estimated to be within $10 \%$ of the corresponding value.

\begin{tabular}{ccccc}
\hline $\mathbf{X}$ & POM:CD & {$\left[\mathrm{XW}_{12} \mathrm{O}_{40}\right]^{3-}$} & {$\left[\mathrm{XW}_{12} \mathrm{O}_{40}\right]^{4-}$} & {$\left[\mathrm{XW}_{12} \mathrm{O}_{40}\right]^{5^{5-}}$} \\
\hline \multirow{2}{*}{$\mathrm{P}$} & $1: 1$ & 90000 & 6000 & 0 \\
& $1: 2$ & 1500 & 30 & 0 \\
\multirow{3}{*}{$\mathrm{Si}$} & $1: 1$ & - & 9500 & 130 \\
& $1: 2$ & - & 150 & 0 \\
\multirow{3}{*}{$\mathrm{B}$} & $1: 1$ & - & - & 600 \\
& $1: 2$ & - & - & 0 \\
\hline
\end{tabular}

This electrochemical study enabled to restore a logical sequence within the Keggin-type series, corroborating the fact that the $\mathrm{POM} / \mathrm{Y}-\mathrm{CD}$ association is mainly related to the global charge of POMs. For instance, plotting $\log K_{1: 1}$ versus the ionic charge of the Keggin-type anion results in a quite perfect linear relationship (see ESI, Fig. S10). Furthermore, analysis of the electrochemical data provides access to the binding constants of the lower oxidation states of the Keggin anions (see Table 2 ). The binding constants of the reduced $\mathrm{POM}^{(\mathrm{n}+1)-}$ exhibit lower values compared to those determined for the oxidized parent $\left(\mathrm{POM}^{\mathrm{n}-}\right)$, evidencing again the preponderant effect of the charge on the association process with the macrocyclic host. For instance, the binding constants of the one-electron reduced $\left[\mathrm{PW}_{12} \mathrm{O}_{40}\right]^{4-}$ anion $\left(K_{1: 1}=6000 \mathrm{M}^{-1}\right)$ fall in similar range order to that found for the oxidized silicotungstate $\left[\mathrm{SiW}_{12} \mathrm{O}_{40}\right]^{4-}$ $\left(K_{1: 1}=9500 \mathrm{M}^{-1}\right)$ (see Table 2$)$. A similar observation is made for the one electron-reduced silicotungstate $\left[\mathrm{SiW}_{12} \mathrm{O}_{40}\right]^{5-}$ and the oxidized borotungstate $\left[\mathrm{BW}_{12} \mathrm{O}_{40}\right]^{5-}$, which both exhibit comparable affinity toward $\gamma$-cyclodextrin. Besides, such a trend can be compared to results reported in a previous study which demonstrated that decreasing the ionic charge of a rhenium-selenide cluster $\left[\operatorname{Re}_{6} \mathrm{Se}_{8}(\mathrm{CN})_{6}\right]^{4-}$ through a oneelectron oxidative process provokes a dramatic increase of the $K_{1: 1}$ binding constant from $1.5 \times 10^{3}$ to $2.2 \times 10^{5} \mathrm{M}^{-1} .^{34}$ Nevertheless, alteration of the redox properties through supramolecular interactions remains quite intriguing in the case of the Keggin-type polyoxometalates. $\gamma$-CD being a nonionic component, its interaction with POM does not change the ionic charge as observed generally with protons or lithium ions. In context, Proton-Coupled Electron Transfer (PCET) involving POM species is a well-known $\mathrm{pH}$ dependent process featured by an increase of the standard potential as $p H$ decreases. Such an effect can even be extended to POMlithium aggregation process under reducing conditions in nonaqueous solvents. ${ }^{52}$ In the presence of $\gamma-C D$, the origin of the redox potential variation upon $\gamma-C D$ interaction should arise mostly from a change in the solvation shell of the POM corresponding to a shed of surrounding water molecules upon binding to $\gamma-C D$ resulting in a more hydrophobic environment around the POMs. The influence of the medium, i.e. solvent and electrolyte support, on the redox properties of the POM species is well documented experimentally as well as through theoretical calculations and related studies reinforce our interpretation of the $\gamma$-CD effect upon the redox properties of Keggin-type POMs. ${ }^{53,54}$ For instance, the first one-electron wave of the $\left[\mathrm{SiW}_{12} \mathrm{O}_{40}\right]^{4-}$ ion undergoes a $600-700 \mathrm{mV}$ potential shift toward the negative potential when the medium is changed from aqueous to organic such as acetonitrile or dimethyl sulfoxide. This effect has been attributed to the capacity of the solvent to stabilize the reduced derivatives and has been quantified by the acceptor number $(A N)$ of the solvent showing that the reduction process becomes difficult as solvent $A N$ decreases. Water exhibits a high $A N$ value (58.4) while less hydrophilic or less polar media feature lower $A N$ parameters. ${ }^{55}$ Furthermore, the intensity of the peak current decreases significantly in the presence of $\gamma-C D$. This behavior accounts for the complexation process which lowers the diffusion coefficient of the parent oxidized POM and then consecutively affects the peak current intensity, according to the Randles-Sevcik equation. ${ }^{56}$ This effect on the current peak intensity appears quite pronounced in the CVs of the $\left[\mathrm{PW}_{12} \mathrm{O}_{40}\right]^{3-}$ ion, which exhibits the strongest affinity with the $\gamma$ $C D$ and diminishes as the ionic charge of the POM increases. Diffusion coefficient change upon $\gamma-C D$ complexation is also nicely supported by ${ }^{1} \mathrm{H}$ DOSY NMR study presented below.

To sum up, electrochemical investigations demonstrate that the binding constants $K_{1: 1}$ and $K_{1: 2}$ increase by at least one order of magnitude as the global ionic charge decreases along the Keggin-type series $\left[\mathrm{XW}_{12} \mathrm{O}_{40}\right]^{\mathrm{n}-}$. From this observation, the Keggin $/ \gamma-C D$ association appears as an appealing component for redox switches, and could be integrated into design stimuliresponsive supramolecular systems controlled by the redox state of the POMs.

\section{NMR spectroscopy}

The formation and stability of Keggin POM $/ \gamma-C D$ complexes in aqueous solution were further probed by ${ }^{1} \mathrm{H} \quad \mathrm{NMR}$ spectroscopy in $\mathrm{D}_{2} \mathrm{O}$. In previous separate studies, the interaction of $\gamma-\mathrm{CD}$ with both $\left[\mathrm{PW}_{12} \mathrm{O}_{40}\right]^{3-}$ and $\left[\mathrm{SiW}_{12} \mathrm{O}_{40}\right]^{4-}$ has been characterized by ${ }^{1} \mathrm{H}$ NMR. ${ }^{39,45}$ Here, we conducted a comparative titration study of $2 \mathrm{mM}$ aqueous $\gamma-\mathrm{CD}$ solution with the four Keggin-type anions. Fig. 4 shows the resulting ${ }^{1} \mathrm{H}$ NMR spectra in the range $3.7-4.5 \mathrm{ppm}$ corresponding to the resonance domain of the most exposed protons to guest species, namely $\mathrm{H} 3$ and $\mathrm{H} 5$ are located inside the cavity and $\mathrm{H} 6$ on the top of the secondary rim (see Fig. 1 for protons numbering scheme and ESI Figs. S11-14 for the complete ${ }^{1} \mathrm{H}$ NMR spectra). These protons are the most sensitive to hostguest contact and are usually used as indicators to probe the inclusion phenomenon. 

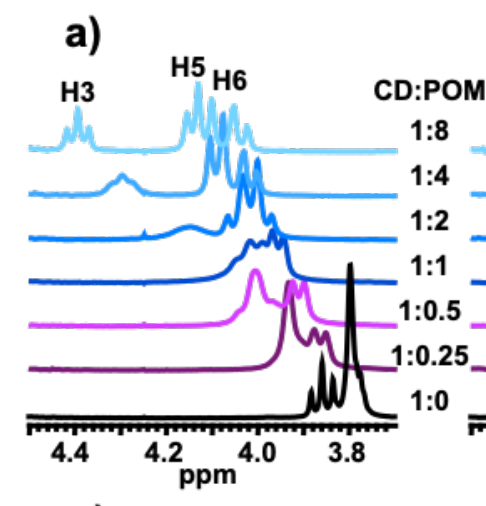

b)
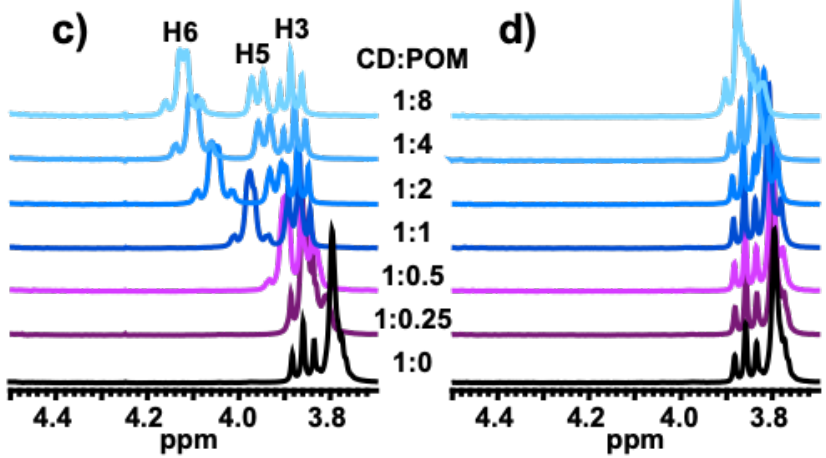

Fig. $4{ }^{1} \mathrm{H}$ NMR spectra in the chemical shift range for $\mathrm{H} 3, \mathrm{H} 5$, and $\mathrm{H} 6$ resulting from the titration of 2 mmol. $L^{-1}$ aqueous $Y-C D$ solution with $\left[\mathrm{XW}_{12} \mathrm{O}_{40}\right]^{\mathrm{n}-} \mathrm{POMs}$. (a) $\left[\mathrm{PW}_{12} \mathrm{O}_{40}\right]^{3-}$; (b) $\left[\mathrm{SiW}_{12} \mathrm{O}_{40}\right]^{4-}$; (c) $\left[\mathrm{BW}_{12} \mathrm{O}_{40}\right]^{5-}$ and (d) $\left[\mathrm{H}_{2} \mathrm{~W}_{12} \mathrm{O}_{40}\right]^{6-}$.

Depending on the Keggin anion, the spectra underwent more or less strong alteration evidencing POM-specific recognition. Table 3 summarizes the extent of shift variations observed for $\mathrm{H} 3, \mathrm{H} 5$, and $\mathrm{H} 6$ after adding eight equivalents of each Keggin-type POM. As expected, the ${ }^{1} \mathrm{H}$ NMR spectrum of the macrocyclic host remains nearly unchanged when $\left[\mathrm{H}_{2} \mathrm{~W}_{12} \mathrm{O}_{40}\right]^{6-}$ was added to the $\gamma-\mathrm{CD}$ solution, and the maximum shifts observed were ca. $0.07 \mathrm{ppm}$ for both $\mathrm{H} 5$ and $\mathrm{H} 6$ indicating very weak interaction. Notably, much bigger effects were observed in the cases of $\left[\mathrm{BW}_{12} \mathrm{O}_{40}\right]^{5-}$ and $\left[\mathrm{SiW}_{12} \mathrm{O}_{40}\right]^{4-}$, where shifts up to 0.33 and $0.18 \mathrm{ppm}$ were observed for $\mathrm{H} 6$ and $\mathrm{H} 5$, respectively. These changes in the spectra are similar that suggests comparable behavior in solution for $\left[\mathrm{BW}_{12} \mathrm{O}_{40}\right]^{5-}$ and $\left[\mathrm{SiW}_{12} \mathrm{O}_{40}\right]^{4-}$. Nevertheless, close inspection revealed some differences. First, the $\mathrm{H} 6$ (and also $\mathrm{H} 5)$ signal evolves much more significantly with increasing the $\left[\mathrm{SiW}_{12} \mathrm{O}_{40}\right]^{4-}$ amount compared to $\left[\mathrm{BW}_{12} \mathrm{O}_{40}\right]^{5-}$ although the final chemical shift at the highest ratio is the same. As the observed chemical shift corresponds to a weighted average of free and complexed $\gamma$-CD species, this means the binding constant of POM-CD complexation should be higher with $\left[\mathrm{SiW}_{12} \mathrm{O}_{40}\right]^{4-}$ than with $\left[\mathrm{BW}_{12} \mathrm{O}_{40}\right]^{5-}$. The second observation is the splitting of the initial singlet of the $\mathrm{H} 6$ protons into two unresolved doublets in $\left[\mathrm{BW}_{12} \mathrm{O}_{40}\right]^{5-}$ containing solution. This may be due to constrained dynamic rotation of the methoxy arms which narrows the signal of the two methylenic diastereotopic $\mathrm{H} 6$ protons. Such steric hindrance would result from the interaction of the POM specifically with the primary rim of the $\gamma$-CD since the $\mathrm{H} 3$ protons present in the secondary rim did not show any significant perturbation. The situation is totally different with $\left[\mathrm{PW}_{12} \mathrm{O}_{40}\right]^{3-}$ anion where besides the shift of $\mathrm{H} 6$, we can also appreciate strong effects on both $\mathrm{H} 5$ and $\mathrm{H} 3$ resonances with up to 0.53 and $0.36 \mathrm{ppm}$ downfield shifts, respectively, indicating involvement of the secondary face of the $\gamma-C D$ in the strong interaction with $\left[\mathrm{PW}_{12} \mathrm{O}_{40}\right]^{3-}$. Furthermore, we note the line broadening of $\mathrm{H} 3$ signal for $P O M: \gamma-C D$ ratio lower than two which is the signature of strong $\mathrm{POM} / \gamma-\mathrm{CD}$ interactions involved in a 1:2 stoichiometry supramolecular adduct. ${ }^{57}$

Table 3 Differences in chemical shifts (ppm) of protons $\mathrm{H} 3, \mathrm{H} 5$, and $\mathrm{H} 6$ of $\gamma$-CD before and after addition of eight equivalents of POM.

\begin{tabular}{cccc}
\hline POM & $\Delta \delta \mathbf{H 3}$ & $\Delta \delta \mathbf{H 5}$ & $\Delta \delta \mathbf{H 6}$ \\
\hline$\left[\mathrm{H}_{2} \mathrm{~W}_{12} \mathrm{O}_{40}\right]^{6-}$ & 0.02 & 0.06 & 0.07 \\
{$\left[\mathrm{BW}_{12} \mathrm{O}_{40}\right]^{5-}$} & 0.03 & 0.18 & 0.33 \\
{$\left[\mathrm{SiW}_{12} \mathrm{O}_{40}\right]^{4-}$} & 0.03 & 0.16 & 0.30 \\
{$\left[\mathrm{PW}_{12} \mathrm{O}_{40}\right]^{3-}$} & 0.53 & 0.36 & 0.28 \\
\hline
\end{tabular}

By analyzing the chemical shifts variation arising from fast chemical exchange regime, quantitative treatment allows for a determination of the binding constants for 1:1 POM: $\gamma-C D$ complexes (for further details, see Figs. S15-16, ESI). The values obtained for $K_{1: 1}$ are 23 and $1100 \mathrm{M}^{-1}$ for $\left[\mathrm{H}_{2} \mathrm{~W}_{12} \mathrm{O}_{40}\right]^{6-}$ $: \mathrm{CD}$ and $\left[\mathrm{BW}_{12} \mathrm{O}_{40}\right]^{5-}: \mathrm{CD}$, respectively, that compare well with the ITC and electrochemistry results (see Tables 1 and 2). In summary, NMR results are fully consistent with electrochemistry showing that the interaction strength with $\gamma$ CD increases following this order: $\left[\mathrm{H}_{2} \mathrm{~W}_{12} \mathrm{O}_{40}\right]^{6-}<\left[\mathrm{BW}_{12} \mathrm{O}_{40}\right]^{5-}<$ $\left[\mathrm{SiW}_{12} \mathrm{O}_{40}\right]^{4-}<\left[\mathrm{PW}_{12} \mathrm{O}_{40}\right]^{3-}$.

Further quantitative investigations were also carried out using DOSY NMR. This technique is a valuable tool to study dynamic equilibriums, and similarly to chemical shift, the observed diffusion coefficient $D$ in the fast exchange limit can be described as a weighted average of a given species evolving between different states. ${ }^{58}$ Thus, the NMR observable of $\gamma-C D$ in presence of POM corresponds to an average situation weighted on residency times between free (solvated) and bound states. The observed diffusion coefficients $D$ as a function of POM: $\gamma-C D$ molar ratio produce different profiles depending on the nature of the Keggin-type anions (see Fig. 5). From the initial value for solvated $\gamma$-CD measured at 254 $\mu \mathrm{m}^{2} / \mathrm{s}$, the self-diffusion $D$ drops more or less abruptly upon addition of POM and reaches a plateau at large excess of POM at $226 \mu \mathrm{m}^{2} / \mathrm{s}$ in the case of $\left[\mathrm{SiW}_{12} \mathrm{O}_{40}\right]^{4-}$ and $\left[\mathrm{BW}_{12} \mathrm{O}_{40}\right]^{5-}$, while for the $\left[\mathrm{H}_{2} \mathrm{~W}_{12} \mathrm{O}_{40}\right]^{6-}$ ion, the decrease of the self-diffusion coefficient draws a smooth slope featured by larger selfdiffusion values as an indication of very weak POM- $\gamma-C D$ interactions. For the $\left[\mathrm{PW}_{12} \mathrm{O}_{40}\right]^{3-}$ ions, the $D$ profile is characteristic of strong interactions. The decrease of $D$ is sharper, reaching even the lower limit value measured at 219 $\mu \mathrm{m}^{2} / \mathrm{s}$. We note also a minimum value for the curves of both $\left[\mathrm{SiW}_{12} \mathrm{O}_{40}\right]^{4-}$ and $\left[\mathrm{PW}_{12} \mathrm{O}_{40}\right]^{3-}$ at ca. $\mathrm{POM}: \gamma-\mathrm{CD}=0.5$ suggesting presence of bulkier intermediate species at these compositions. Both curve profiles have been modeled 
satisfactorily using either a one-step complexation model for $\left[\mathrm{H}_{2} \mathrm{~W}_{12} \mathrm{O}_{40}\right]^{6-}$ and $\left[\mathrm{BW}_{12} \mathrm{O}_{40}\right]^{5-}$ or a two-step complexation model for $\left[\mathrm{SiW}_{12} \mathrm{O}_{40}\right]^{4-}$ and $\left[\mathrm{PW}_{12} \mathrm{O}_{40}\right]^{3-}$. Simulations of these curves considering binding constants consistent with those determined previously from ITC, electrochemistry and also 1D NMR studies allowed to estimate diffusion coefficients of $\gamma-C D$ within $1: 1$ and $1: 2$ adducts. Fair agreements between calculated and experimental data were found using $D$ values of 226 and $163 \mu \mathrm{m}^{2} / \mathrm{s}$ for POM@CD and POM@2CD adducts, respectively. Noteworthy, the same $D$ values were used for the $1: 1$ or $1: 2$ adduct independently of the nature of the Keggintype anion (see ESI for details of modeling, Figs. S17-20), considering similar volume/size for the POM-CD adduct along the Keggin-type series. The observed lower limit value for $D$ with $\left[\mathrm{PW}_{12} \mathrm{O}_{40}\right]^{3-}\left(219\right.$ vs $226 \mu \mathrm{m}^{2} / \mathrm{s}$, see ESI for modeling, Fig. S20) highlights the remarkable solution behavior of the phosphotungstate ion as reported by Antonio et al. ${ }^{59}$ In this composition domain, it may result from some further aggregation which could be consistent with a $\gamma$-CD unit sandwiched by two $\left[\mathrm{PW}_{12} \mathrm{O}_{40}\right]^{3-}$ ions interacting with both primary and secondary faces of the $\gamma-\mathrm{CD}$. This hypothesis is also quite consistent with the ${ }^{1} \mathrm{H}$ NMR titration which reveals interactions involving simultaneously both rims of the $\gamma$-CD.

Furthermore, ${ }^{1} \mathrm{H}$ NMR can also characterize the protoncontaining $\left[\mathrm{H}_{2} \mathrm{~W}_{12} \mathrm{O}_{40}\right]^{6-}$ anion exhibiting a resonance at ca. 6.0 ppm. Very small changes in the diffusion coefficient $D$ (245$260 \mu \mathrm{m}^{2} / \mathrm{s}$ ) were observed over the titration experiment, reflecting very weak interaction with $\gamma-C D$ as previously identified.

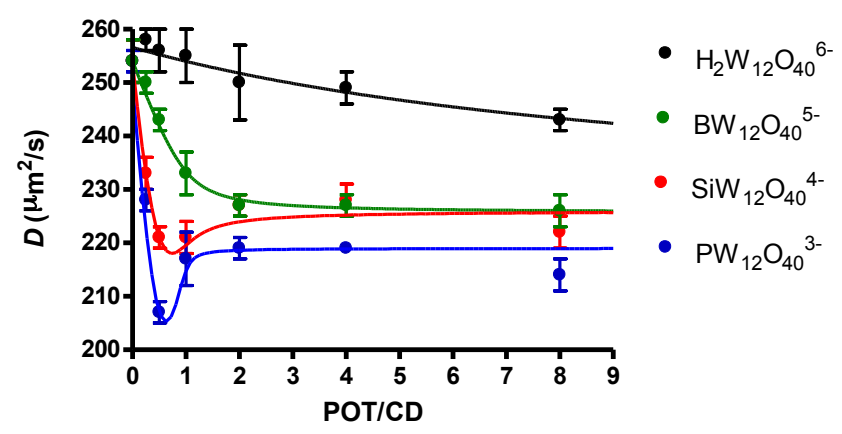

Fig. 5 Diffusion coefficients of $\gamma-C D$ as a function of POM: $\gamma-C D$ molar ratio, measured from ${ }^{1} \mathrm{H}$ DOSY NMR of a solution of $2 \mathrm{mM}$ of $\gamma$-CD with various POM content. Lines correspond to calculated curves with one-step 1:1 POM:CD complexation for $\left[\mathrm{H}_{2} \mathrm{~W}_{12} \mathrm{O}_{40}\right]^{6-}$ and $\left[\mathrm{BW}_{12} \mathrm{O}_{40}\right]^{5-}$, and with two-step 1:2 POM:CD complexation for $\left[\mathrm{SiW}_{12} \mathrm{O}_{40}\right]^{4-}$ and $\left[\mathrm{PW}_{12} \mathrm{O}_{40}\right]^{3-}$.

\section{Driving force of the aggregation processes}

This comparative study evidences clearly that Keggin-type anions bind to $\gamma$-CD with different extents despite their isostructure. Although $\gamma-C D$ is non-ionic, the charge of the POM plays a dramatic role in the molecular recognition process, both in its thermodynamic stability and in its supramolecular structure. All experimental measurements (ITC, electrochemistry and $\mathrm{NMR}$ ) have shown that the interaction with $\left[\mathrm{H}_{2} \mathrm{~W}_{12} \mathrm{O}_{40}\right]^{6-}$ is very weak $\left(\mathrm{K}_{1: 1} \approx 2.3 \times 10^{1} \mathrm{M}^{-1}\right)$, while it is very strong with $\left[\mathrm{PW}_{12} \mathrm{O}_{40}\right]^{3-}\left(\mathrm{K}_{1: 1} \approx 1.6 \times 10^{5} \mathrm{M}^{-1}\right)$. It was proposed that the binding affinity is related to the charge density of the polyanion, which has an effect on the hydration strength, i.e. hydration free energy of the ions. The monotonous trend observed along the oxidized derivatives of the Keggin-type series could be understood by thermodynamic features of the hydration shell around the POM, which is directly related to its chaotropic nature. The weak charge density of the Keggin-type POM generates a loosely bound solvation shell of disordered water molecules with high structural entropy. The energy gain associated to the release of this hydration water into the bulk upon binding to non-ionic moieties (at micellar surfaces, water surfactant monolayer or macrocycles) was proposed as the main driving force of the superchaotropic effect of POMs and more generally of low charge density nano-ions. ${ }^{22}$ The evolution of the cloud point of a non-ionic surfactant, tetra-ethylene glycol mono-octyl ether $\left(\mathrm{C}_{8} \mathrm{E}_{4}\right)$, upon addition of POMs was proposed as a tool to evaluate their chaotropic behavior ${ }^{22}$ : The higher the observed cloud point increase, the stronger the interaction with the non-ionic surfactant and the stronger the chaotropic nature of the tested ion. This procedure was carried out for the Keggintype anions investigated here. Corresponding to the respective increase in the cloud point by each POM, Fig. 6 illustrates an increase in the chaotropic nature of the polyanions from $\left[\mathrm{H}_{2} \mathrm{~W}_{12} \mathrm{O}_{40}\right]^{6-}$ to $\left[\mathrm{PW}_{12} \mathrm{O}_{40}\right]^{3-}$, i.e. from high to low charge density. The superchaotropic $\mathrm{P}-, \mathrm{Si}-$ and B-Keggin POMs produce much stronger increases in the cloud point compared to the classical chaotrope $\mathrm{SCN}^{-}$. The resulting ordering of POMs according to their chaotropic behavior is in full agreement with the series obtained by electrochemistry and NMR measurements.

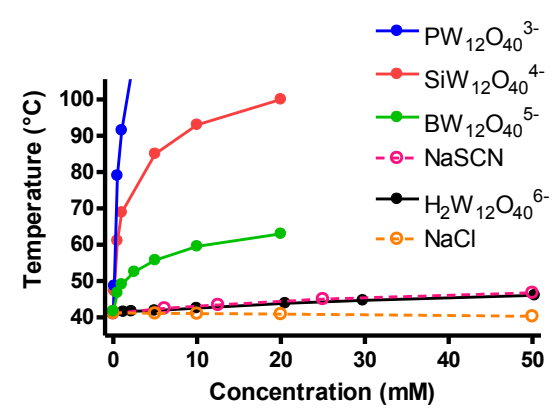

Fig. 6 Cloud point evolutions of $60 \mathrm{mM} \mathrm{C}_{8} \mathrm{E}_{4}$ as a function of salt concentration for the four isostructural Keggin-ions $\mathrm{PW}_{12} \mathrm{O}_{40}{ }^{3-}, \mathrm{SiW}_{12} \mathrm{O}_{40}{ }^{4-}, \mathrm{BW}_{12} \mathrm{O}_{40}{ }^{5-}$ and $\mathrm{H}_{2} \mathrm{~W}_{12} \mathrm{O}_{40}{ }^{6-}$. The classical salts $\mathrm{NaCl}$ (neutral salt) and $\mathrm{NaSCN}$ (classical chaotropic salt) are included as references.

SAXS measurements provided further insight into the superchaotropic character of the Keggin POMs (see Figs. S21 and $\mathrm{S} 22, \mathrm{ESI}$ ). $\mathrm{H}_{2} \mathrm{~W}_{12} \mathrm{O}_{40}{ }^{6-}$ in the presence of $\mathrm{C}_{8} \mathrm{E}_{4}$ shows identical scattering as in bare water, while with $\mathrm{BW}_{12} \mathrm{O}_{40}{ }^{5-}$ a strong oscillation appears, which is even more pronounced with $\mathrm{SiW}_{12} \mathrm{O}_{40}{ }^{4-}$. This oscillation is characteristic of core-shell structuration and typical of POM-decorated micelles. The increase of the oscillation with the superchaotropic character of the Keggin-ion is a direct indicator of the extent of adsorption onto the $\mathrm{C}_{8} \mathrm{E}_{4}$-micelles resulting in the same 
ordering as in other experiments: $\mathrm{SiW}_{12} \mathrm{O}_{40}{ }^{4-}>\mathrm{BW}_{12} \mathrm{O}_{40}{ }^{5-}>$ $\mathrm{H}_{2} \mathrm{~W}_{12} \mathrm{O}_{40}{ }^{6-}$. It is worthy to note that in the case of $\mathrm{PW}_{12} \mathrm{O}_{40}{ }^{3-}$ precipitation occurs in the presence of $\mathrm{C}_{8} \mathrm{E}_{4}$ micelles, preventing SAXS measurement. Nevertheless, precipitate formation hints at a particularly strong interaction of $\mathrm{Na}_{3} \mathrm{PW}_{12} \mathrm{O}_{40}$ with the surfactant.

Overall, we showed herein that the Keggin-type POMs interact with the $\gamma-C D$ through various recognition modes depending on the POM's chaotropic power. The different interaction types previously identified can be classified along the Keggin ion series related to the magnitude of the binding constants. As tentatively depicted in Fig. 7, lowering of the ionic charge gives rise to multimodal supramolecular processes consistent with our experimental observations. On the left side of the scale, the $\left[\mathrm{H}_{2} \mathrm{~W}_{12} \mathrm{O}_{40}\right]^{6-}$ ion shows nearly no ability to interact with $\gamma-C D$ and the $\left[\mathrm{BW}_{12} \mathrm{O}_{40}\right]^{5-}$ species reveals only weak interactions that involve preferably the outer surface of the $C D$ as observed in the crystal structure of $\mathbf{B W}_{\mathbf{1 2}} \cdot \mathbf{2 C D}$ (see Fig. 2c). Lowering further the ionic charge down to $\left[\mathrm{SiW}_{12} \mathrm{O}_{40}\right]^{4-}$ ion leads to the formation of $1: 1$ and $1: 2$ inclusion complexes involving mostly the primary face featuring higher binding constants. Finally, on the right side, the lowest ionic charge anion $\left[\mathrm{PW}_{12} \mathrm{O}_{40}\right]^{3-}$ gives rise to the highest binding constants reflected in the large diversity of supramolecular binding modes. As shown previously by ${ }^{1} \mathrm{H} N M R$, both primary and secondary faces contribute to the POM's complexation and complementary DOSY NMR study suggested even the presence of an unusual supramolecular assembly corresponding to a $\gamma$ $\mathrm{CD}$ sandwiched by two $\left[\mathrm{PW}_{12} \mathrm{O}_{40}\right]^{3-}$ anion. Despite the lack of any structural model for such an arrangement, NMR showed clearly that in excess of POM, the primary face represented by $\mathrm{H} 5$ and $\mathrm{H} 6$ resonances and the secondary face detected by $\mathrm{H} 3$ resonances are both simultaneously involved in low selfdiffusion coefficient assembly compatible with a $\{$ POM $\cdots$ CD $\cdots$ POM $\}$ arrangement. The binding on the primary and secondary faces of the $C D$, which results in a large contact surface with the POM, is favored over the binding of POMs on the exterior side of the $C D$.

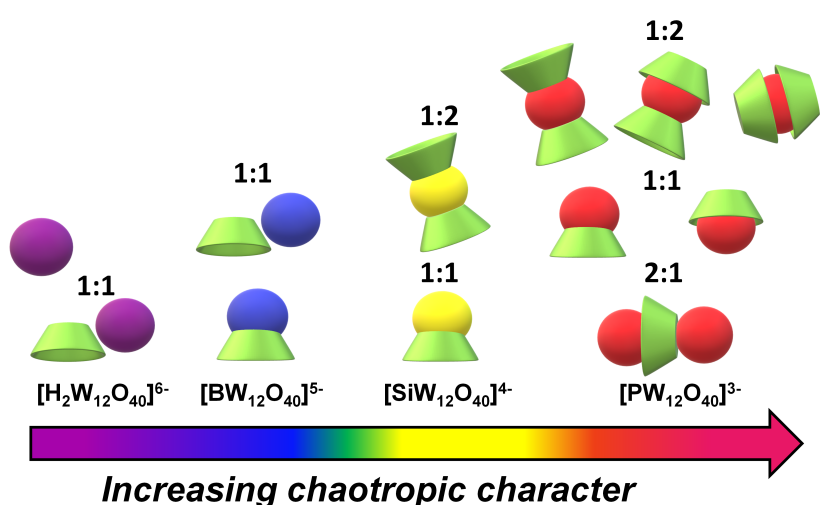

Fig. 7 Illustration of the most representative binding modes involved in the supramolecular assemblies of $\gamma-C D$ (green torus) and the Keggin anions (spheres).

\section{Conclusions}

A comparative study allowed for an establishment of the relationship between the ionic charge of Keggin-type polyoxotungstate anions and their affinity towards a non-ionic substrate, $\gamma$-cyclodextrin. As the charge is lowered systematically keeping molecular size and shape, the ability to form supramolecular complexes increases continuously as was also observed for the interaction of the POMs with non-ionic surfactant micelles. The effects governing such supramolecular assemblies are suggested to be directly related to the solvation properties of the Keggin ions and to their propensity to shed hydration water upon formation of POM-substrate contact. While the most charged POMs, $\left[\mathrm{H}_{2} \mathrm{~W}_{12} \mathrm{O}_{40}\right]^{6-}$ and $\left[\mathrm{BW}_{12} \mathrm{O}_{40}\right]^{5-}$ showed weak to moderate affinity towards $\gamma-C D$, interacting mainly with its exterior wall, the lowest charge density species formed sandwich-type host-guest complexes involving either the primary face or the secondary face, featuring larger shared interfaces. Thus, in the Keggin-type series, the $\left[\mathrm{PW}_{12} \mathrm{O}_{40}\right]^{3-}$ ion previously identified as a superchaotrope ${ }^{60}$ exhibits a remarkable capacity to bind $\gamma-C D$ through its two faces, thus presenting unique aggregation behavior. The host-guest adaptability allows maximizing contact interfaces through weak dispersion forces, highly amplified through a solvent effect arising from the pronounced superchaotropic nature of the $\left[\mathrm{PW}_{12} \mathrm{O}_{40}\right]^{3-}$ ion. This remarkable solution behavior of the $\left[\mathrm{PW}_{12} \mathrm{O}_{40}\right]^{3-}$ ion is not restricted to the systems involving cyclodextrins and the present study gives a better understanding for other self-assembly processes involving non-ionic substrates in water. ${ }^{21,59,61,62}$ Furthermore, POM/CD association has dramatic consequences on the POM's redox properties, i.e. a decrease in the standard redox potential. This effect can be understood as a partial removal of the hydration shell of the redox active ions arising from the presence of bulky $\gamma-C D$ in the close vicinity of the POM. It is worth noting that opposite effects corresponding to a redox potential increase were commonly observed for interaction with cations such as protonation or ion-pairing with lithium cation.

Finally, the propensity of the Keggin-type anions to bind to $\gamma$-CD can be dramatically tuned by reversible electron transfer as demonstrated herein. This opens opportunities for the design of smart molecular materials like sensors, artificial muscles, and actuators, responsive to redox or possibly light stimuli.

\section{Experimental section}

\section{Chemicals}

All reagents were purchased from commercial sources and used without further purification. $\mathrm{K}_{4.3} \mathrm{Na}_{0.7}\left[\mathrm{BW}_{12} \mathrm{O}_{40}\right] \bullet 17 \mathrm{H}_{2} \mathrm{O},{ }^{63}$ $\mathrm{H}_{5}\left[\mathrm{BW}_{12} \mathrm{O}_{40}\right] \cdot 29 \mathrm{H}_{2} \mathrm{O},{ }^{64} \quad \mathrm{~K}_{4}\left[\mathrm{SiW}_{12} \mathrm{O}_{40}\right] \cdot 6 \mathrm{H}_{2} \mathrm{O},{ }^{65}$ $\mathrm{Na}_{0.6} \mathrm{H}_{3.4}\left[\mathrm{SiW}_{12} \mathrm{O}_{40}\right] \bullet 16 \mathrm{H}_{2} \mathrm{O},{ }^{66} \quad \mathrm{~K}_{3}\left[\mathrm{PW}_{12} \mathrm{O}_{40}\right] \bullet 5 \mathrm{H}_{2} \mathrm{O}$, $\mathrm{Na}_{1.4} \mathrm{H}_{1.6}\left[\mathrm{PW}_{12} \mathrm{O}_{40}\right] \cdot 12 \mathrm{H}_{2} \mathrm{O}$, and $\mathrm{H}_{3}\left[\mathrm{PW}_{12} \mathrm{O}_{40}\right] \bullet 14 \mathrm{H}_{2} \mathrm{O}^{65,67}$ were prepared according to literature procedures and checked by routine analyses prior using. The synthesis of $\mathrm{Rb}_{6}\left[\mathrm{H}_{2} \mathrm{~W}_{12} \mathrm{O}_{40}\right] \cdot 11 \mathrm{H}_{2} \mathrm{O}$ is described below. Solutions were prepared in MilliQ-water. 


\section{Materials characterization}

\section{Fourier Transform Infrared (FT-IR)}

Spectra were recorded on a 6700 FT-IR Nicolet spectrophotometer, using diamond ATR technique. The spectra were recorded on non-diluted compounds and ATR correction was applied.

\section{Energy-dispersive X-ray spectroscopy}

EDS measurements were performed using a SEM-FEG (Scanning Electron Microscope enhanced by a Field Emission Gun) equipment (JSM 7001-F, Jeol). The measures were acquired with a SDD XMax $50 \mathrm{~mm}^{2}$ detector and the Aztec (Oxford) system working at $15 \mathrm{kV}$ and $10 \mathrm{~mm}$ working distance. The quantification is realized with the standard library provided by the constructor using L $\alpha$ lines.

\section{Thermal gravimetric analysis (TGA)}

To determine water and organic contents, a Mettler Toledo TGA/DSC 1, STAR ${ }^{\mathrm{e}}$ System apparatus was used under oxygen or nitrogen flow $\left(50 \mathrm{~mL} \mathrm{~min}{ }^{-1}\right)$ at a heating rate of $5{ }^{\circ} \mathrm{C} \mathrm{min}^{-1}$ up to $700{ }^{\circ} \mathrm{C}$.

\section{Single-Crystal X-ray diffraction analysis}

Intensity data collections were carried out at $T=200(2) \mathrm{K}$ with a Bruker D8 VENTURE diffractometer equipped with a PHOTON 100 CMOS bidimensional detector using a high brilliance $\mathrm{I} \mu \mathrm{S}$ microfocus $\mathrm{X}$-ray Mo $\mathrm{K} \alpha$ monochromatized radiation $(\lambda=0.71073 \AA$ ). Crystals were glued in paratone oil to prevent any loss of crystallization water. Data reduction was accomplished using SAINT V7.53a. The substantial redundancy in data allowed a semi-empirical absorption correction (SADABS V2.10) to be applied, on the basis of multiple measurements of equivalent reflections. Using Olex2, ${ }^{68}$ the structure was solved with the ShelXT ${ }^{69}$ structure solution program using Intrinsic Phasing and refined with the ShelXL ${ }^{70}$ refinement package using Least Squares minimization. Heavier atoms (W) for each structure were initially located by direct methods. The remaining nonhydrogen atoms were located from Fourier differences and were refined with anisotropic thermal parameters. Positions of the hydrogen atoms belonging to the $\gamma$-CDs were calculated and refined isotropically using the gliding mode. In the compound PW 12@CD, numerous free water molecules $\left(\mathrm{H}_{2} \mathrm{O}\right)$ located inside the voids are disordered. Thereby the contribution of solvent-electron density was removed using the SQUEEZE routine in PLATON, producing a set of solvent-free diffraction intensities. Crystallographic data for single-crystal X-ray diffraction studies are summarized in Table S1.

\section{Isothermal Titration Calorimetry (ITC)}

Formation constants and inclusion enthalpies were simultaneously determined for each $\gamma$-CD/POM system by the use of an isothermal calorimeter (ITC200, MicroCal Inc., USA). Degassed deionized water solutions were used in both cell $\left(\mathrm{V}_{0}\right.$ $=202.8 \mu \mathrm{L})$ and syringe $(40 \mu \mathrm{L})$. After addition of an initial aliquot of $2 \mu \mathrm{L}, 10$ aliquots of $3.5 \mu \mathrm{L}$ of the syringe solution were delivered over $7 \mathrm{~s}$ for each injection. The time interval between two consecutive injections was $70 \mathrm{~s}$, which proved to be sufficient for a systematic and complete return to baseline. The agitation speed was set to $1000 \mathrm{rpm}$. The resulting heat flow was recorded as a function of time. ITC titrations were realized at three temperatures $(288,298$ and $308 \mathrm{~K})$, with 5 $\mathrm{mM} \gamma$-CD solution in the syringe and $0.25 \mathrm{mM}$ POM solution in the cell. Values and uncertainties of formation constants and inclusion enthalpies were determined by global analysis of the binding isotherms, by means of a dedicated homemade program, ${ }^{71}$ implementing $1: 1$ and 1:1+1:2 binding polynomials.

\section{Electrochemistry}

Purified water was used throughout. It was obtained by passing water through a RiOs 8 unit followed by a Millipore- $Q$ Academic purification set. All reagents were of high-purity grade and were used as purchased without further purification. Cyclic voltammetric (CV) experiments were carried out with an Methrohm Autolab PGSTAT12 potentiostat/galvanostat associated with a GPES electrochemical analysis system (EcoChemie). Measurements were performed at room temperature in a conventional single compartment cell. A glassy carbon (GC) electrode with a diameter of $3 \mathrm{~mm}$ was used as the working electrode. The auxiliary electrode was a Pt plate placed within a fritted-glass isolation chamber and potentials are quoted against a saturated calomel electrode (SCE). The solutions were deaerated thoroughly for at least $\mathbf{3 0}$ minutes with pure argon and kept under a positive pressure of this gas during the experiments.

\section{Nuclear Magnetic Resonance (NMR)}

All solution NMR spectra were measured in $\mathrm{D}_{2} \mathrm{O}$ at $26{ }^{\circ} \mathrm{C} .{ }^{1} \mathrm{H}$ NMR spectra were obtained on a Bruker Avance 400 spectrometer at a Larmor frequency of $400.1 \mathrm{MHz}$, using $5 \mathrm{~mm}$ standard NMR tubes. The $1 \mathrm{D}{ }^{1} \mathrm{H}$ spectra were recorded with one pulse sequence at $30^{\circ}$ flip angle (pulse duration $2.7 \mu \mathrm{s}$ ), using $0.1 \mathrm{~s}$ recycle delay, $3 \mathrm{~s}$ acquisition time, and 8 number of scans. Translational diffusion measurements were performed using Bruker's "ledbpgs2s" stimulated echo DOSY pulse sequence including bipolar and spoil gradients. Apparent diffusion coefficients were obtained using an adapted algorithm based on the inverse Laplace transform stabilized by maximum entropy. ${ }^{72}$ Chemical shifts are reported relative to tetramethylsilane (TMS).

\section{Cloud point measurements}

Aqueous solutions containing $60 \mathrm{mM} \mathrm{C}_{8} \mathrm{E}_{4}$ and a given amount of POM were prepared into $1 \mathrm{~mL}$ glass vials. The vials were placed in a temperature controlled water bath. The heating rate was constant at $1 \mathrm{~K} \cdot \mathrm{min}^{-1}$ and the $\mathrm{CP}$ was detected by visual inspection after occurrence of turbidity. The choice of the counter-ion has negligible effects on the cloud point evolution. $^{22}$

\section{Syntheses}




\section{$\mathrm{Rb}_{4.5} \mathrm{Na}_{1.5}\left[\mathrm{H}_{2} \mathrm{~W}_{12} \mathrm{O}_{40}\right] \cdot 11 \mathrm{H}_{2} \mathrm{O}$}

The synthetic procedure is inspired from the syntheses of the tetraalkylammonium (TAA) salts, TAA ${ }_{6}\left[\mathrm{H}_{2} \mathrm{~W}_{12} \mathrm{O}_{40}\right] \bullet 9 \mathrm{H}_{2} \mathrm{O}^{73}$ $\mathrm{Na}_{2} \mathrm{WO}_{4} \cdot 2 \mathrm{H}_{2} \mathrm{O}(10 \mathrm{~g}, 30 \mathrm{mmol})$ is dissolved in $30 \mathrm{~mL}$ of deionized water, and the resulted solution is acidified with $\mathrm{HCl}$ $\left(6 \mathrm{~mol}^{-1} \mathrm{~L}^{-1}\right)$ till $\mathrm{pH} \sim 3$. The solution is kept boiling for $24 \mathrm{~h}$ and the $\mathrm{pH}$ remains at 3 . After cooling to room temperature, the solution is then filtered, and rubidium chloride $(5.5 \mathrm{~g}, 45$ $\mathrm{mmol}$ ) is added. The white solid product is collected, and finally dried in air. Yield: $3.8 \mathrm{~g}(33 \%)$. IR $\left(\mathrm{cm}^{-1}\right)$ : 956 (sh), 935 (s), 896 (s), 878 (s), 766 (vs), ${ }^{183}$ W NMR: -117.6 ppm; ${ }^{1} \mathrm{H}$ NMR: $5.99 \mathrm{ppm}$. ICP-OES Anal. Calcd for $\mathrm{H}_{24} \mathrm{Na}_{1.5} \mathrm{O}_{51} \mathrm{Rb}_{4.5} \mathrm{~W}_{12}$ : $\mathrm{Na}$, 1.00; Rb, 11.10; $\mathrm{W}, 63.66$. Found: $\mathrm{Na}, 0.9 ; \mathrm{Rb}, 10.5 ; \mathrm{W}, 58.0$. TGA showed a weight loss of $5.5 \%$ in the $20-220{ }^{\circ} \mathrm{C}$ temperature range corresponding to the eleven hydration water molecules (calculated 5.7\%).

\section{$\mathrm{CsK}_{2} \mathrm{H}_{2}\left\{\left[\mathrm{BW}_{12} \mathrm{O}_{40}\right] \cdot 2\left(\mathrm{C}_{48} \mathrm{H}_{80} \mathrm{O}_{40}\right)\right\} \cdot 29 \mathrm{H}_{2} \mathrm{O}\left(\mathrm{BW}_{12} \cdot 2 \mathrm{CD}\right)$}

A mixture of $\mathrm{K}_{4.3} \mathrm{Na}_{0.7}\left[\mathrm{BW}_{12} \mathrm{O}_{40}\right] \cdot 17 \mathrm{H}_{2} \mathrm{O}(68 \mathrm{mg} ; 0.02 \mathrm{mmol}$ ) and $\gamma-\mathrm{CD}(85 \mathrm{mg} ; 0.06 \mathrm{mmol})$ in $3.5 \mathrm{~mL}$ aqueous solution of $\mathrm{CsCl}\left(0.05 \mathrm{~mol} . \mathrm{L}^{-1}\right)$ and $\mathrm{KCl}\left(0.1 \mathrm{~mol} . \mathrm{L}^{-1}\right)$ was stirred until obtaining a clear solution. The solution was then allowed to stand for crystallization in air. Colorless crystals of $\mathbf{B W}_{\mathbf{1 2}} \cdot \mathbf{2} \mathbf{C D}$ were obtained by slow ethanol vapor diffusion into water solution (10 mL vessel containing $2 \mathrm{~mL}$ of water solution was placed into a $250 \mathrm{~mL}$ vessel with a tight-fitting lid containing 50 $\mathrm{mL}$ of ethanol) after 3 days, and were collected, washed with mixture water/ethanol and dried on air. Yield $37 \mathrm{mg}, 30 \%$. FTIR spectrum is given in Fig. S23. ICP-OES Anal. Calcd for $\mathrm{BC}_{1.5} \mathrm{CsH}_{220} \mathrm{~K}_{2} \mathrm{O}_{149} \mathrm{~W}_{12}$ : B, 0.17; C, 18.64; $\mathrm{K}, 1.26 ; \mathrm{W}, 35.66$. Found: $\mathrm{B}, 0.2 ; \mathrm{C}, 18.5 ; \mathrm{K}, 1.2 ; \mathrm{W}, 32.5$. EDS showed $\mathrm{Cs}: \mathrm{K}: \mathrm{W}$ ratio $=1.7: 2.1: 12$. TGA showed a weight loss of $8.4 \%$ in the 20-220 ${ }^{\circ} \mathrm{C}$ temperature range corresponding to the twentynine hydration water molecules (calculated $8.4 \%$ ) and a weight loss of $42 \%$ in the $220-700{ }^{\circ} \mathrm{C}$ range assigned to the loss of 2 CD (calculated $41.1 \%$ ).

\section{$\mathrm{Na}_{3}\left\{\left[\mathrm{PW} \mathbf{1 2}_{12} \mathrm{O}_{40}\right] \cdot\left(\mathrm{C}_{48} \mathrm{H}_{80} \mathrm{O}_{40}\right)\right\} \cdot 10 \mathrm{H}_{\mathbf{2}} \mathrm{O}\left(\mathrm{PW} \mathbf{1 2}_{12} @ \mathrm{CD}\right)$}

$\mathrm{Na}_{1.4} \mathrm{H}_{1.6}\left[\mathrm{PW}_{12} \mathrm{O}_{40}\right] \cdot 12 \mathrm{H}_{2} \mathrm{O}(0.3 \mathrm{~g} ; 0.096 \mathrm{mmol})$ is dissolved in $10 \mathrm{~mL}$ aqueous solution of $\mathrm{NaCl}\left(0.2 \mathrm{~mol}^{-\mathrm{L}^{-1}}\right)$ and $\gamma-\mathrm{CD}(0.138 \mathrm{~g}$; $0.096 \mathrm{mmol}$ ) was added. The clear solution is stirred for 15 min. The solution was then allowed to stand for crystallization in air. Needle-like colorless crystals of PW $\mathbf{1 2} @$ CD suitable for single crystal X-ray diffraction appeared within 5 days. They were isolated by filtration and washed with cold water. Yield $0.35 \mathrm{~g}, 76 \%$. FT-IR spectrum is given in Fig. S24. ICP-OES Anal. Calcd for $\mathrm{C}_{48} \mathrm{H}_{100} \mathrm{Na}_{3} \mathrm{O}_{90} \mathrm{PW}_{12}$ : C, 13.03; $\mathrm{Na}, 1.56 ; \mathrm{P}, 0.70 ; \mathrm{W}$, 49.87. Found: $C, 12.8 ; \mathrm{Na}, 1.6 ; \mathrm{P}, 0.7 ; \mathrm{W}, 48.9$. EDS showed $\mathrm{Na}$ : $\mathrm{P}: \mathrm{W}$ ratio $=2.7: 1.1: 12$. TGA showed a weight loss of $3.9 \%$ in the $20-220{ }^{\circ} \mathrm{C}$ temperature range corresponding to the ten hydration water molecules (calculated $4.1 \%$ ) and a weight loss of $26.8 \%$ in the $220-700{ }^{\circ} \mathrm{C}$ range assigned to the loss of $1.3 \mathrm{CD}$ (calculated 27\%).

\section{Conflicts of interest}

There are no conflicts of interests to declare.

\section{Acknowledgements}

This work is supported by a public grant overseen by the French National Research Agency as part of the "Investissements d'Avenir" program (Labex Charm3at, ANR11-LABX-0039-grat). This research is also supported by the China Scholarship Council (CSC) to S. Y. (201904910419). Authors are grateful to Flavien Bourdreux and Cyrielle Rey for their help for elemental analyses.

\section{Notes and references}

1 M. Pope Heteropoly and Isopoly Oxometalates; Springer-Verlag: Berlin Heidelberg, 1983.

2 N. I. Gumerova and A. Rompel, Synthesis, structures and applications of electron-rich polyoxometalates, Nat. Rev. Chem., 2018, 2, 20.

3 J. J. Chen, M. D. Symes and L. Cronin, Highly reduced and protonated aqueous solutions of $\mathrm{P}_{2} \mathrm{~W}_{18} \mathrm{O}_{62}{ }^{6-}$ for on-demand hydrogen generation and energy storage, Nat. Chem., 2018, 10, 1042 .

4 B. Huang, D. H. Yang and B. H. Han, Application of polyoxometalate derivatives in rechargeable batteries, J. Mater. Chem. A, 2020, 8, 4593.

5 Y. Nishimoto, D. Yokogawa, H. Yoshikawa, K. Awaga and S. Irle, Super-Reduced Polyoxometalates: Excellent Molecular Cluster Battery Components and Semipermeable Molecular Capacitors, J. Am. Chem. Soc., 2014, 136, 9042.

6 L. E. VanGelder, A. M. Kosswattaarachchi, P. L. Forrestel, T. R. Cook and E. M. Matson, Polyoxovanadate-alkoxide clusters as multielectron charge carriers for symmetric nonaqueous redox flow batteries, Chem. Sci., 2018, 9, 1692.

7 H. Wang, S. Hamanaka, Y. Nishimoto, S. Irle, T. Yokoyama, H. Yoshikawa and K. Awaga, In Operand X-ray Absorption Fine Structure Studies of Polyoxometalate Molecular Cluster Batteries: Polyoxometalates as Electron Sponges, J. Am. Chem. Soc., 2012, 134, 4918.

8 H. N. Wang, M. Zhang, A. M. Zhang, F. C. Shen, X. K. Wang, S. N. Sun, Y. J. Chen and Y. Q. Lan, Polyoxometalate-Based Metal-Organic Frameworks with Conductive Polypyrrole for Supercapacitors, ACS Appl. Mater. Interfaces, 2018, 10, 32265.

9 B. R. Limoges, R. J. Stanis, J. A. Turner and A. M. Herring, Electrocatalyst materials for fuel cells based on the polyoxometalates $\mathrm{PMo}_{12-\mathrm{n}} \mathrm{V}_{\mathrm{n}} \mathrm{O}_{40}{ }^{(3+n)-}(\mathrm{n}=0-3)$, Electrochim. Acta, 2005, 50, 1169.

10 W. Liu, W. Mu, M. J. Liu, X. D. Zhang, H. L. Cai and Y. L. Deng, Solar-induced direct biomass-to-electricity hybrid fuel cell using polyoxometalates as photocatalyst and charge carrier, Nat. Commun., 2014, 5, 8 .

11 M. Blasco-Ahicart, J. Soriano-Lopez, J. J. Carbo, J. M. Poblet and J. R. Galan-Mascaros, Polyoxometalate electrocatalysts based on earth-abundant metals for efficient water oxidation in acidic media, Nat. Chem., 2018, 10, 24.

12 M. Bonchio, Z. Syrgiannis, M. Burian, N. Marino, E. Pizzolato, K. Dirian, F. Rigodanza, G. A. Volpato, G. La Ganga, N. Demitri, S. Berardi, H. Amenitsch, D. M. Guldi, S. Caramori, C. A. Bignozzi, A. Sartorel and M. Prato, Hierarchical organization of perylene bisimides and polyoxometalates for photo-assisted water oxidation, Nat. Chem., 2019, 11, 146.

13 G. Paille, M. Gomez-Mingot, C. Roch-Marchal, M. Haouas, Y. Benseghir, T. Pino, M. H. Ha-Thi, G. Landrot, P. Mialane, M. 
Fontecave, A. Dolbecq and C. Mellot-Draznieks, Thin Films of Fully Noble Metal-Free POM@MOF for Photocatalytic Water Oxidation, ACS Appl. Mater. Interfaces, 2019, 11, 47837.

14 J. Tourneur, B. Fabre, G. Loget, A. Vacher, C. Meriadec, S. Ababou-Girard, F. Gouttefangeas, L. Joanny, E. Cadot, M. Haouas, N. Leclerc-Laronze, C. Falaise and E. Guillon, Molecular and Material Engineering of Photocathodes Derivatized with PolyoxometalateSupported $\left\{\mathrm{Mo}_{3} \mathrm{~S}_{4}\right\}$ HER Catalysts, J. Am. Chem. Soc., 2019, 141, 11954.

15 M. Stuckart and K. Y. Monakhov, Polyoxometalates as components of supramolecular assemblies, Chem. Sci., 2019, 10, 4364.

16 S. Chakraborty, A. S. Grego, S. Garai, M. Baranov, A. Muller and I. A. Weinstock, Alcohols as Latent Hydrophobes: Entropically Driven Uptake of 1,2-Diol Functionalized Ligands by a Porous Capsule in Water, J. Am. Chem. Soc., 2019, 141, 9170.

17 S. Kopilevich, H. Gottlieb, K. Keinan-Adamsky, A. Muller and I. A. Weinstock, The Uptake and Assembly of Alkanes within a Porous Nanocapsule in Water: New Information about Hydrophobic Confinement, Angew. Chem.-Int. Edit., 2016, 55, 4476.

18 A. Misra, K. Kozma, C. Streb and M. Nyman, Beyond Charge Balance: Counter-Cations in Polyoxometalate Chemistry, Angew. Chem.-Int. Edit., 2020, 59, 596.

19 N. Watfa, D. Melgar, M. Haouas, F. Taulelle, A. Hijazi, D. Naoufal, J. B. Avalos, S. Floquet, C. Bo and E. Cadot, Hydrophobic Effect as a Driving Force for Host-Guest Chemistry of a MultiReceptor Keplerate-Type Capsule, J. Am. Chem. Soc., 2015, 137, 5845.

20 P. C. Yin, D. Li and T. B. Liu, Solution behaviors and self-assembly of polyoxometalates as models of macroions and amphiphilic polyoxometalate-organic hybrids as novel surfactants, Chem. Soc. Rev., 2012, 41, 7368.

21 T. Buchecker, P. Schmid, I. Grillo, S. Prevost, M. Drechsler, O. Diat, A. Pfitzner and P. Bauduin, Self-Assembly of Short Chain Poly$\mathrm{N}$-isopropylacrylamid Induced by Superchaotropic Keggin Polyoxometalates: From Globules to Sheets, J. Am. Chem. Soc., 2019, 141, 6890.

22 T. Buchecker, P. Schmid, S. Renaudineau, O. Diat, A. Proust, A. Pfitzner and P. Bauduin, Polyoxometalates in the Hofmeister series, Chem. Commun., 2018, 54, 1833.

23 D. Kobayashi, H. Nakahara, O. Shibata, K. Unoura and H. Nabika, Interplay of Hydrophobic and Electrostatic Interactions between Polyoxometalates and Lipid Molecules, J. Phys. Chem. C, 2017, 121, 12895.

24 A. Malinenko, A. Jonchere, L. Girard, S. Parres-Maynadie, O. Diat and P. Bauduin, Are Keggin's POMs Charged Nanocolloids or Multicharged Anions?, Langmuir, 2018, 34, 2026.

25 M. A. Moussawi, M. Haouas, S. Floquet, W. E. Shepard, P. A. Abramov, M. N. Sokolov, V. P. Fedin, S. Cordier, A. Ponchel, E. Monflier, J. Marrot and E. Cadot, Nonconventional ThreeComponent Hierarchical Host-Guest Assembly Based on Mo-Blue Ring-Shaped Giant Anion, gamma-Cyclodextrin, and Dawson-type Polyoxometalate, J. Am. Chem. Soc., 2017, 139, 14376.

26 M. A. Moussawi, N. Leclerc-Laronze, S. Floquet, P. A. Abramov, M. N. Sokolov, S. Cordier, A. Ponchel, E. Monflier, H. Bricout, D. Landy, M. Haouas, J. Marrot and E. Cadot, Polyoxometalate, Cationic Cluster, and gamma-Cyclodextrin: From Primary Interactions to Supramolecular Hybrid Materials, J. Am. Chem. Soc., 2017, 139, 12793.

27 B. Naskar, O. Diat, V. Nardello-Rataj and P. Bauduin, Nanometer-Size Polyoxometalate Anions Adsorb Strongly on Neutral Soft Surfaces, J. Phys. Chem. C, 2015, 119, 20985.
28 T. J. Paul, T. N. Parac-Vogt, D. Quinonero and R. Prabhakar, Investigating Polyoxometalate-Protein Interactions at Chemically Distinct Binding Sites, J. Phys. Chem. B, 2018, 122, 7219.

29 A. Solé-Daura, J. M. Poblet and J. J. Carbo, Structure-Activity Relationships for the Affinity of Chaotropic Polyoxometalate Anions towards Proteins, Chem.-Eur. J., 2020, 26, 5799.

30 Y. L. Wu, R. F. Shi, Y. L. Wu, J. M. Holcroft, Z. C. Liu, M. Frasconi, M. R. Wasielewski, H. Li and J. F. Stoddart, Complexation of Polyoxometalates with Cyclodextrins, J. Am. Chem. Soc., 2015, 137, 4111.

31 K. I. Assaf and W. M. Nau, The Chaotropic Effect as an Assembly Motif in Chemistry, Angew. Chem.-Int. Edit., 2018, 57, 13968.

32 K. I. Assaf, M. S. Ural, F. F. Pan, T. Georgiev, S. Simova, K. Rissanen, D. Gabel and W. M. Nau, Water Structure Recovery in Chaotropic Anion Recognition: High-Affinity Binding of Dodecaborate Clusters to -Cyclodextrin, Angew. Chem.-Int. Edit., 2015, 54, 6852.

33 M. Hohenschutz, I. Grillo, O. Diat and P. Bauduin, How NanoIons Act Like Ionic Surfactants, Angew. Chem.-Int. Edit., 2020, 59, 8084.

34 A. A. Ivanov, C. Falaise, D. Landy, M. Haouas, Y. V. Mironov, M. A. Shestopalov and E. Cadot, Tuning the chaotropic effect as an assembly motif through one-electron transfer in a rhenium cluster, Chem. Commun., 2019, 55, 9951.

35 G. Zhang, B. Keita, C. T. Craescu, S. Miron, P. de Oliveira and L. Nadjo, Polyoxometalate binding to human serum albumin: A thermodynamic and spectroscopic approach, J. Phys. Chem. B, 2007, 111, 11253.

36 D. Prochowicz, A. Kornowicz and J. Lewinski, Interactions of Native Cyclodextrins with Metal Ions and Inorganic Nanoparticles: Fertile Landscape for Chemistry and Materials Science, Chem. Rev., 2017, 117, 13461.

37 C. Falaise, M. A. Moussawi, S. Floquet, P. A. Abramov, M. N. Sokolov, M. Haouas and E. Cadot, Probing Dynamic Library of Metal-Oxo Building Blocks with gamma-Cyclodextrin, J. Am. Chem. Soc., 2018, 140, 11198.

38 P. Su, A. J. Smith, J. Warneke and J. Laskin, Gas-Phase Fragmentation of Host-Guest Complexes of Cyclodextrins and Polyoxometalates, J. Am. Soc. Mass Spectrom., 2019, 30, 1934.

39 Y. X. Fan, S. F. Lu and J. Cao, A novel inorganic-organic hybrid complex between polyoxometalate and cyclodextrin: Synthesis, structure and catalytic activity, Int. J. Mass Spectrom., 2019, 435, 163.

40 Y. X. Fan, Y. Zhang, Q. D. Jia, J. Cao and W. J. Wu, The Stabilizing Role of Cyclodextrins on Keggin Phosphotungstic Acid by Complexation Unveiled by Electrospray Mass Spectrometry, Mass Spectrom. Lett., 2015, 6, 13.

41 L. B. Ni, H. Li, H. J. Xu, C. Shen, R. Z. Liu, J. Xie, F. M. Zhang, C. Chen, H. X. Zhao, T. F. Zuo and G. W. Diao, Self-Assembled Supramolecular Polyoxometalate Hybrid Architecture as a Multifunctional Oxidation Catalyst, ACS Appl. Mater. Interfaces, 2019, 11, 38708.

42 B. Pacaud, L. Leclercq, J. F. Dechezelles and V. Nardello-Rataj, Hybrid Core-Shell Nanoparticles by "Plug and Play" Self-Assembly, Chem.-Eur. J., 2018, 24, 17672.

43 B. Zhang, W. M. Guan, F. F. Yin, J. X. Wang, B. Li and L. X. Wu, Induced chirality and reversal of phosphomolybdate cluster via modulating its interaction with cyclodextrins, Dalton Trans., 2018, 47, 1388 .

44 P. Yang, W. L. Zhao, A. Shkurenko, Y. Belmabkhout, M. Eddaoudi, X. C. Dong, H. N. Alshareef and N. M. Khashab, Polyoxometalate-Cyclodextrin Metal-Organic Frameworks: From 
Tunable Structure to Customized Storage Functionality, J. Am. Chem. Soc., 2019, 141, 1847.

45 Z. G. Jiang, W. T. Mao, Y. W. Huang, Y. Wang, X. J. Wang and C. H. Zhan, Nonconventional Host-Guest Cubic Assembly Based on $\gamma^{-}$ Cyclodextrin and Keggin-type Polyoxometalate, Nanoscale, 2020, 12, 10166.

46 A. A. Ivanov, C. Falaise, K. Laouer, F. Hache, P. Changenet, Y. V. Mironov, D. Landy, Y. Molard, S. Cordier, M. A. Shestopalov, M. Haouas and E. Cadot, Size-Exclusion Mechanism Driving Host-Guest Interactions between Octahedral Rhenium Clusters and Cyclodextrins, Inorg. Chem., 2019, 58, 13184.

47 S. Himeno, M. Takamoto, R. Santo and A. Ichimura, Redox properties and basicity of Keggin-type polyoxometalate complexes, Bull. Chem. Soc. Jpn., 2005, 78, 95.

48 K. Kamata and K. Sugahara, Base Catalysis by Mono- and Polyoxometalates, Catalysts, 2017, 7, 24.

49 M. V. Rekharsky and Y. Inoue, Complexation thermodynamics of cyclodextrins, Chem. Rev., 1998, 98, 1875.

50 K. I. Assaf, B. Begaj, A. Frank, M. Nilam, A. S. Mougharbel, U. Kortz, J. Nekvinda, B. Gruner, D. Gabel and W. M. Nau, High-Affinity Binding of Metallacarborane Cobalt Bis(dicarbollide) Anions to Cyclodextrins and Application to Membrane Translocation, J. Org. Chem., 2019, 84, 11790.

51 K. I. Assaf, J. Holub, E. Bernhardt, J. M. Oliva-Enrich, M. I. F. Perez, M. Canle, J. A. Santaballa, J. Fanfrlik, D. Hnyk and W. M. Nau, Face-Fusion of Icosahedral Boron Hydride Increases Affinity to gamma-Cyclodextrin: closo,closo- $\mathrm{B} 21 \mathrm{H} 18(-)$ as an Anion with Very Low Free Energy of Dehydration, ChemPhysChem, 2020, 21, 971. 52 T. Konishi, K. Kodani, T. Hasegawa, S. Ogo, S. X. Guo, J. F. Boas, J. Zhang, A. M. Bond and T. Ueda, Impact of the lithium cation on the voltammetry and spectroscopy of $\left[\mathrm{XVM}_{11} \mathrm{O}_{40}\right]^{\mathrm{n-}}(\mathrm{X}=\mathrm{P}, \mathrm{As}(\mathrm{n}=4), \mathrm{S}$ $(n=3) ; M=M o, W)$ : Influence of chrage and addenda and hetero atoms, Inorg. Chem., 2020, under press, DOI: 10.1021/acs.inorgchem.0c00876.

53 S. X. Guo, A. W. A. Mariotti, C. Schlipf, A. M. Bond and A. G. Wedd, A Systematic approach to the simulation of the voltammetric reduction of alpha-SiW $\mathrm{S}_{12} \mathrm{O}_{40}{ }^{4-}$ in buffered aqueous electrolyte media and acetonitrile, J. Electroanal. Chem., 2006, 591, 7.

54 M. Sadakane and E. Steckhan, Electrochemical properties of polyoxometalates as electrocatalysts, Chem. Rev., 1998, 98, 219.

55 V. Gutmann, Emperical parameters for donor and acceptor properties of solvents, Electrochim. Acta, 1976, 21, 661.

56 A. J. Bard and L. R. Faulkener Electrochemical Methods: Fundamentals and Applications; John Wiley \& Sons ed.: New York, 2001.

57 A. A. Ivanov, C. Falaise, P. A. Abramov, M. A. Shestopalov, K. Kirakci, K. Lang, M. A. Moussawi, M. N. Sokolov, N. G. Naumov, S. Floquet, D. Landy, M. Haouas, K. A. Brylev, Y. V. Mironov, Y. Molard, S. Cordier and E. Cadot, Host-Guest Binding Hierarchy within Redoxand Luminescence-Responsive Supramolecular Self-Assembly Based on Chalcogenide Clusters and gamma-Cyclodextrin, Chem.-Eur. J., 2018, 24, 13467.

58 Y. Cohen, L. Avram, T. Evan-Salem, S. Slovak, N. Shemesh and L. Frish In Analytical Methods in Supramolecular Chemistry; Schalley, C. A., Ed.; John Wiley \& Sons, Ltd, 2012, 197.

59 M. R. Antonio and M. K. Bera, pH-Dependent Interactions between Keggin Heteropolyanions in Dilute Solutions, Eur. J. Inorg. Chem., 2019, 367.

60 C. Drummond, L. Perez-Fuentes and D. Bastos-Gonzalez, Can Polyoxometalates Be Considered as Superchaotropic lons?, J. Phys. Chem. C, 2019, 123, 28744.
61 M. K. Bera and M. R. Antonio, Crystallization of Keggin Heteropolyanions via a Two-Step Process in Aqueous Solutions, J. Am. Chem. Soc., 2016, 138, 7282.

62 M. K. Bera, B. F. Qiao, S. Seifert, B. P. Burton-Pye, M. O. de la Cruz and M. R. Antonio, Aggregation of Heteropolyanions in Aqueous Solutions Exhibiting Short-Range Attractions and LongRange Repulsions, J. Phys. Chem. C, 2016, 120, 1317.

$63 \mathrm{H}$. Fletcher, C. C. Allen, R. C. Burns and D. C. Craig, Pentapotassium dodecatungstoborate(III) hexadecahydrate, Acto Crystallogr. Sect. C-Cryst. Struct. Commun., 2001, 57, 505.

64 C. Rocchicciolideltcheff, M. Fournier, R. Franck and R. Thouvenot, Vibrational investigations of polyoxometalates. 2. Evidence for anion anion interactions in molybdenum(VI) and tungsten(VI) compounds related to the Keggin structure, Inorg. Chem., 1983, 22, 207.

65 P. Souchay lons Minéraux Condensés; Masson \& Cie ed.: Paris, 1969.

66 A. Tézé and G. Hervé In Inorg. Synth.; John Wiley \& Sons, 1990; Vol. 27, 85

$67 \mathrm{H}$. Wu, Contribution to the chemistry of phosphomolybdic acids, phosphotungstic acids, and allied substances, J. Biol. Chem., 1920, 43, 189.

68 O. V. Dolomanov, L. J. Bourhis, R. J. Gildea, J. A. K. Howard and H. Puschmann, OLEX2: a complete structure solution, refinement and analysis program, J. Appl. Crystallogr., 2009, 42, 339.

69 G. M. Sheldrick, SHELXT - Integrated space-group and crystalstructure determination, Acta Crystallogr. Sect. A, 2015, 71, 3.

70 G. M. Sheldrick, Crystal structure refinement with SHELXL, Acto Crystallogr. Sect. C-Struct. Chem., 2015, 71, 3.

71 E. Bertaut and D. Landy, Improving ITC studies of cyclodextrin inclusion compounds by global analysis of conventional and nonconventional experiments, Beilstein J. Org. Chem., 2014, 10, 2630.

$72 \mathrm{M}$. A. Delsuc and T. E. Malliavin, Maximum entropy processing of DOSY NMR spectra, Anal. Chem., 1998, 70, 2146.

$73 \mathrm{M}$. Asami, H. Ichida and Y. Sasaki, The structure of hexakis(tetramethylammonium)dihydrogendodecatungstate enneahydrate, $\left(\left(\mathrm{CH}_{3}\right)_{4} \mathrm{~N}\right)_{6} \mathrm{H}_{2} \mathrm{~W}_{12} \mathrm{O}_{40} \cdot 9 \mathrm{H}_{2} \mathrm{O}$, Acta Crystallogr. Sect. CCryst. Struct. Commun., 1984, 40, 35. 